\title{
Article \\ Models of Optimal Operating Modes of the Water-Economic Complex on the Basis of Hydro Resource Price Evaluation
}

\author{
Yury Sekretarev ${ }^{1}$, Tatyana Myateg ${ }^{1} \mathbb{D}$, Aminjon Gulakhmadov $2,3,4,5 \mathbb{D}$, Murodbek Safaraliev ${ }^{6}(\mathbb{D}$, \\ Sergey Mitrofanov ${ }^{1} \mathbb{D}$, Natalya Zubova ${ }^{1}$, Olga Atamanova ${ }^{7}$ and Xi Chen ${ }^{2,3,8, *}$
}

\section{check for} updates

Citation: Sekretarev, Y.; Myateg, T.; Gulakhmadov, A.; Safaraliev, M.; Mitrofanov, S.; Zubova, N.; Atamanova, O.; Chen, X. Models of Optimal Operating Modes of the Water-Economic Complex on the Basis of Hydro Resource Price Evaluation. Mathematics 2022, 10, 765 . https://doi.org/10.3390/math10050765

Academic Editors: Svetlana

V. Solodusha and Pastor Manuel

Received: 13 December 2021

Accepted: 21 February 2022

Published: 27 February 2022

Publisher's Note: MDPI stays neutral with regard to jurisdictional claims in published maps and institutional affiliations.

Copyright: (c) 2022 by the authors Licensee MDPI, Basel, Switzerland. This article is an open access article distributed under the terms and conditions of the Creative Commons Attribution (CC BY) license (https:// creativecommons.org/licenses/by/ $4.0 /)$.
1 Department of Power Supply System, Novosibirsk State Technical University, 630073 Novosibirsk, Russia; sekretarevua@mail.ru (Y.S.); tatianamyateg@mail.ru (T.M.); mitrofanov@corp.nstu.ru (S.M.); zubova@corp.nstu.ru (N.Z.)

2 Research Center for Ecology and Environment of Central Asia, Xinjiang Institute of Ecology and Geography, Chinese Academy of Sciences, Urumqi 830011, China; aminjon@ms.xjb.ac.cn

3 State Key Laboratory of Desert and Oasis Ecology, Xinjiang Institute of Ecology and Geography, Chinese Academy of Sciences, Urumqi 830011, China

4 Ministry of Energy and Water Resources of the Republic of Tajikistan, Dushanbe 734064, Tajikistan

5 Institute of Water Problems, Hydropower and Ecology, National Academy of Sciences of Tajikistan, Dushanbe 734042, Tajikistan

6 Department of Automated Electrical Systems, Ural Federal University, 620002 Yekaterinburg, Russia; murodbek_03@mail.ru

7 Department of Foreign Languages of Engineering Faculties, Novosibirsk State Technical University, 630073 Novosibirsk, Russia; osa1952@list.ru

8 University of Chinese Academy of Sciences, Beijing 100049, China

* Correspondence: chenxi@ms.xjb.ac.cn

Abstract: The purpose of this article is to solve the problem of determining the cost of a water resource for the participants of the water-economic complex (WEC) on the basis of the optimal control of hydro power plants' (HPP) functioning, taking into account their regime characteristics and requirements. In this work, a universal method, which combines an optimization method and a method for assessing marginal utility, was proposed to assess the cost of the hydro resource and control the operating modes of the WEC. The method developed by the authors involves the use of water balance, the adequate representation of the incremental rate characteristic and the determination of the cost of the hydro resource for the control of the operating modes of the WEC and HPP. Using the example of the Novosibirsk WEC, as well as HPPs and TPPs, an assessment of the energy efficiency, proposing the concept of a developed methodology for determining the price of water for HPPs and all participants in the WEC, will be obtained. Based on the results of the implementation of the developed approach at Novosibirsk HPPs, the electricity sales price competitive electricity market can be matched with the electricity sales price generated at TPP, which will be approximately $0.16 \not / \mathrm{kW} * \mathrm{~h}$.

Keywords: water utilization system; mutually exclusive and mutually complementary branches; optimization of hydropower plants functioning; marginal utility; water price for hydropower plants; incremental rate characteristic; flexible energy market

\section{Introduction}

At present, the impact of technologies on the environment has become commensurable in scale with the natural processes at our planet. Therefore, it is especially relevant to use renewable energy sources (in particular, water resources) for the energy market, organized as the Internet of Things [1,2]. Then, the determination of a water price in a hydropower plant functioning for the entire water utilization complex (WUC) will increase the ecological and economic efficiency of the national economy of the country in modern conditions, 
thus diminishing the energy of the technological process and the end product of power system operation to zero.

Hydropower plants (HPP) are power plants that use the movement of water masses in channel runoffs and tidal motions as a source of energy. For efficient electricity generation at HPP, two main factors are necessary: a guaranteed supply of water during a year and possibly large river falls (canyon-like relief types are favorable for hydraulic construction) [3,4]. Methodologies for solving optimization problems in the case of HPP cascades are significantly complicated and not fully studied [5-12]. The reason for this was the absence in the 1970s-1980s of the necessary powerful automation tools required for solving such problems [13-18]. At present, when dealing with big data, and when decisionmaking is facilitated for a decision maker by the availability of appropriate super-powerful computing technologies, this problem has been solved [19-24]. Therefore, approaches to solving optimization problems should meet modern requirements [5,25-29].

The aim of this investigation is to optimize the operating modes of HPP based on the determination of a hydro resource price, taking into account HPP operating characteristics. After that, it is possible to calculate the cost of water resources of the entire WUC according to the criterion of ecological and economic efficiency to improve the environmental situation in the regions and in the world as a whole the incremental rate of active power losses due to the power flow of the $i$-th power plant in the network.

The relevance and novelty of the investigation is as follows. Until now, when solving optimization problems in a hydrothermal power system, a Lagrangian multiplier method with a coefficient of the energy value of water $\lambda$ has been used to compare differential characteristics of an equivalent thermal power plant (TPP) and a HPP, which resulted in multi-iteration complex calculations and did not allow the taking into account of the head change at the HPP during $24 \mathrm{~h} \mathrm{[30-33].} \mathrm{In} \mathrm{the} \mathrm{approach} \mathrm{developed} \mathrm{by} \mathrm{the} \mathrm{authors}$ for solving the problem of transition from the differential characteristic of the HPP to the characteristic of the equivalent TPP, it is proposed to use the theory of marginal utility for solving such optimization problems. According to this methodology, indifference curves allow the comparing of the DC at the equivalent TPP and water consumption at HPP in one iteration when covering the daily load schedule, taking into account the head changing during $24 \mathrm{~h}$. This is a new fundamental principle in solving optimization problems in mixed power systems, since it provides a comprehensive approach to solving this problem, taking into account not only the technical features of the functioning of power facilities, but also the optimization of ecological and economic parameters. Thus, a hydro resource price in hydrothermal power systems was determined through the equivalent capacity of thermal power plants and recalculated through the cost of organic fuel, which was saved at the TPP due to the HPP operation. This so-called "interchanging effect" was calculated for a single case, namely the HPP operation in the peak area of the load schedule of the power system. In fact, HPP operating modes in the power system are more diverse. In winter, a hydropower plant draws down the reservoir and operates in the peak area of the load schedule of the power system. During the high-water period in spring, an HPP fills the reservoir and operates in the base area of the load schedule. In addition, for a considerable period in the annual context, a hydropower plant, as a rule, operates in the natural afflux period, i.e., without using the water reservoir capacity.

In addition, a hydropower plant operates as part of a water utilization system, performing other important functions along with the function of generating electricity, namely maintaining guaranteed navigation depths, guaranteed levels for water intake of industrial enterprises and water supply to cities, meeting the requirements of fisheries and agriculture in the field of irrigation [34,35].

Certainly, determining a hydro resource price is different when performing all these functions above, and it cannot be determined through the mentioned "interchanging effect".

Therefore, a hydro resource price is differentiated for performing each function that allows the obtainment of a synergistic effect from the HPP operation, both as part of the power system and as part of the water utilization system. 
It is this ideology that was used in the development of mathematical models and verification of these models on the example of the unified power system of Siberia (UPS of Siberia), where the percentage of HPP in the installed capacity of the power system is approximately $53.5 \%$ (the total capacity of the UPS of Siberia is 52,139.9 MW) [36].

The article has the following structure.

Part one-introduction and relevance of the topic.

The second part presents the general statement of the problem and its critical analysis.

The third part is devoted to a mathematical model for determining the cost of a hydro resource at a hydropower plant to control its operating modes.

The fourth part presents a mathematical model for managing the operating modes of the water management complex. The fifth part is devoted to the practical implementation of the proposed methods and an analysis of the results obtained.

The sixth part contains a discussion.

The conclusions is presented in the seventh part of the article.

\section{General Statement of the Problem and Its Critical Analysis}

An analogue to the proposed methodology is the currently known Lagrangian multiplier method [7,30-33].

Comparative analysis of the most advantageous load distribution in the power system with the representation of expressions (1) [5,7-9]:

$$
\begin{gathered}
\frac{b_{n}}{1-\sigma_{n}}=\lambda * \frac{q_{1}}{1-\sigma_{1}}=\ldots=\lambda * \frac{q_{m}}{1-\sigma_{m}}=\text { idem } \\
\frac{b_{n}}{1-\sigma_{n}}=\lambda_{2} * \frac{q_{1}}{1-\sigma_{1}}=\ldots=\lambda_{2} * \frac{q_{m}}{1-\sigma_{m}}=i d e m
\end{gathered}
$$

where $b_{1}, b_{2}, \ldots, b_{n}$-differential characteristics of $n$ thermal power plants (TPPs);

$q_{1}, q_{2}, \ldots, q_{m}$-relative increase in water consumption at hydropower plants (HPPs);

$\lambda$-conversion factor, the essence of which will be discussed below.

$\frac{\partial \Delta P}{\partial N_{i}}=\sigma_{i}$ is called the incremental rate of active power losses due to the power flow of the $i$-th power plant in the network.

In this case, it is taken into account that the HPP is single (i.e., it is not included in any HPP cascade) and is subjected to annual (seasonal) regulation. At the same time, the head during $24 \mathrm{~h}$ remains constant with rare exceptions, i.e., $H \approx$ const [5]. Thus, the HPP head is assumed to be constant, which significantly simplifies the algorithm for solving the problem. At the same time, one cubic meter of water resources $\left(1 \mathrm{~m}^{3}\right)$ will have almost the same energy for the whole optimization period. This is the disadvantage of the method of the equality of incremental fuel rates proposed in [5].

It should be noted that taking into account network losses complicates the optimization calculations. In this paper, for simplicity and clarity of illustrating the proposed approach to the evaluation of a hydro resource price, the optimization condition is used with the assumption that the incremental rate of losses is not considered.

It should be noted that during optimization TPPs are simulated as generating sources with "unlimited energy resources". This means that any power at a given moment (certainly within the permissible range of power plant operation) is being provided by the energy resource, no matter what load of the power plant took place at the previous time. This provides the basis for combining all TPPs into an equivalent one with mandatory consideration of all technical limitations. In turn, hydropower plants are represented as energy facilities with "limited energy resources", since their volume depends on the water content of the year and the part of the volume of the reservoir between the marks of the optimal highest level of the horizon and the level of the maximum drawdown of the reservoir. In contrast to the TPP at the HPP, the $i$-th value of the volume of electricity generation at it is co-determined by the value of the electricity produced in the $(i-1)$ step. However, it is impossible to reduce hydropower plants into the equivalent HPP, since its volume depends 
on the water content of the year and the part of the volume of the reservoir between the marks of the optimal highest level of the horizon and the level of the maximum drawdown of the reservoir. The generation at an HPP at each moment of time is determined by the value of its power for the previous time interval.

The main physical parameter at the stations for maintaining their optimal mode of operation can be represented by the following expressions:

$$
\begin{aligned}
& b=\frac{\mathrm{d} B}{\mathrm{~d} N} \\
& q=\frac{\mathrm{d} Q}{\mathrm{~d} N}
\end{aligned}
$$

where $B$ is the absolute value of the fuel consumption (toe/hour) and $Q$ is the value of the water resource consumption, $\left(\mathrm{m}^{3} / \mathrm{s}\right)$.

$\lambda$ value is the energy efficiency of using water in a mixed energy system. It is a link between the differential characteristics of an equivalent TPP and an HPP. It is used in optimizing the operating modes of a mixed-type EPS. At the same time, the number of iterations can be 5 and even more, which requires a lot of computer time, meaning a long convergence of the methodology is its obvious disadvantage.

In the methodologies developed earlier, there are two ways of selecting the Lagrangian multiplier $\lambda$ in the presence of a given power system load schedule [5].

In international practice, for the most favorable load distribution between generating facilities, the Pareto optimal set method is used, which shifts the solution of a complex spatial problem into a two-dimensional plane. It does not allow taking into account all the features and the complexity of operation of large power systems occupying the entire territory of Siberia, the Urals and the Far East etc. The dynamic programming method can also be used $[37,38]$. A considerable disadvantage of this method is that its accuracy depends on the value of the quantization step. The smaller the step, the higher the accuracy of calculations. This results in the increase in the memory capacity that is consumed for memorization of energy characteristics. Therefore, this method is difficult to use in automated process control software systems, which are subjected to rather strict requirements for the memory capacity, as well as the solution speed. Another applied method is the principle of the equality of incremental fuel rates, which also has the disadvantage of calculation difficulties and long convergence of the algorithm with a large expenditure of computer time [37-39]. For price formation, the principle of marginal pricing is used. In our opinion, this is not an effective method, because the price is formed based on the costs of the least profitable producer, being quite high [39]. In the WUS of Russia, the methodology of compiling the water balance is used for the optimization of its operating modes [34,35]. The authors of [40] propose an analysis and classification of emergency situations at HPPs for reducing water risks in the WUS. World experience shows that it is proposed to comply with the requirements of the European Directive 2018/851 on waste, along with the observance of the water balance [41-43]. At the same time, one publication [42] pays special attention to methods of combating plastic. However, no attempt has been made for optimization of the WUS operating modes based on the determination of a hydro resource price for all the WUS participants.

Therefore, according to the patent-oriented search, there is no universal methodology for determining a hydro resource's price for HPPs as infrastructure objects and for the whole WUS. Basically, the water charge is used everywhere, with the only difference that it is considerably higher in other countries in comparison with Russian values.

The principle from [42,43] is adopted as a criterion in this article. Based on its use, the authors solve the problem of estimating the cost of water both for HPPs as a participant of the WHC and for the entire WEC. When considering the conditions for optimization in a mixed power system, it is necessary to decide whether the pressure at the HPP will be constant or variable [15-17]. In this case, the features of the operating modes of each branch of the WEC, as well as the need to comply with the overall water balance in order to 
provide reliable water supply to each consumer, are taken into account [34,35]. It should be noted that the developed approach is environmentally friendly, since it allows improving the ecological situation in the regions [44-46].

As during $24 \mathrm{~h}$ the head pressure at any HPP changes insignificantly, most often these changes (with operational control) are not taken into account when determining optimization conditions [47-50].

All thermal power plants are represented by equivalent characteristics: $V e=f(\mathrm{Ne})$; $b e=\mathrm{f}(\mathrm{Ne})$ is the consumption characteristic of the equivalent TPP and the equivalent characteristic of the relative increase in fuel consumption, respectively. Moreover, in this case it is considered that an equivalent TPP combines several combined heat and power plants (CHPP), which are characterized by the forced heating operation cycle [5].

This can be done because TPPs are generating sources with unlimited resources.

It should be noted that to provide the relative increase in water consumption at HPPs and fuel consumption at equivalent TPPs, the method of indefinite Lagrange multipliers is used (with coefficient $\lambda-$ a measure of the efficiency of using hydro resources in the Electric power system (EPS) (dimension of t.f./hour $/ \mathrm{m}^{3} / \mathrm{s}$ ). With an increase in water consumption HPP, $\lambda$-the measure of efficiency decreases $[5,6]$.

With the most advantageous distribution of power within the generating company, power losses in networks should be taken into account [5]. In this investigation, network losses are not considered, because all power plants are located in the territory of the Novosibirsk region.

This is possible because the theory of marginal utility allows us to compare the value of fuel consumption at TPP and water consumption at hydroelectric power plants for the same satisfaction of consumer needs in power based on the use of indifference curves for one iteration [51,52]. Therefore, there is a rationalization of the use of all types of resources-computer time, human, financial, which is more effective in modern conditions. An additional advantage of the developed approach is the ability to take into account the changing value of the head. All this makes it possible to quite simply and quickly determine the hydro resource price for all branches of the WEC. It should be emphasized that until now in the world-wide practice there has not been created a single universal technique for determining the cost of a hydro resource, taking into account the operating characteristics of an HPP.

Another important advantage of the developed methodology in comparison with Russian and foreign analogues is the consideration of the head change during $24 \mathrm{~h}$ that allows the taking into account of the technological features of the HPP functioning in a better way, in contrast to previously used methods $[5,6,13,20]$. In fact, the differential characteristic of an HPP is a family of curves for different values of the head [5].

Previous studies in the area of the problem of calculating the cost of water for the WEC did not provide a solution to the problem facing specialists. The technology presented by the authors will be useful in solving problems of both short-term and long-term optimization of the regimes of generating companies and water and chemical complexes.

A peculiar feature of the developed approach is a fundamentally different approach to the main parameter required for optimization of operating modes and represented by expressions (2) and (3). From the point of view of technical and economic efficiency and the correctness of the solution of the task, it is more correct to use their monetary representation instead of physical parameters.

This article is devoted to the analysis and study of the modes of operation of centralized sources of energy supply, since they form the basis of the Russian energy sector. However, the methodology developed by the authors is also suitable for distributed generation facilities using Smart Grid technologies using TSO and DSO network services, which will create a reserve ring for a centralized power system in relation to Russian conditions, thereby increasing the reliability of its operation $[45,46]$.

This paper discusses such important issues as the possibility of improving the environmental situation and the solution of energy-saving problems in the world based on a careful 
attitude to water resources by estimating the cost of their use for HPPs and the entire WUS and reduction of the use of fossil fuels. Therefore, this methodology is relevant and can be used not only for Russian conditions but also proposed for wide international application. It is universal and easy to calculate in comparison with existing methodologies, as it allows the taking into account of the economic component, which more fully represents the most favorable load distribution in a hydrothermal power system. Moreover, the authors propose a mathematical model for implementation and for optimizing the operating modes of the HPP and the entire WUS based on the determination of a hydro resource price using the HPP operational features. Therefore, in the authors' opinion, this paper is suitable for publication in the Special Issues section of the Mathematics Journal.

\section{Mathematical Model for Determining the Cost of a Hydro Resource for HPPs Based on the Control of HPP Operating Modes}

Since an HPP is an infrastructure industry among all the branches of a water utilization system, it is reasonable to start solving the problem of determining a water price in a WUS with a consideration of this industry [34,35].

However, a strategy for reforming the power engineering industry has been developed, and is being realized at the present time $[40,41]$. This involves the step-by-step transformation of the energy management structure to a two-sided market model, where each consumer will choose their own producer, and the producer is affected by the volume of output of manufactured products and functioning regimes. Typical disadvantages of an existing functioning management principle (criterion for minimizing fuel costs) are the following: (1) discrepancy between a management objective and present conditions when the profit increasing of each business unit will be actual; (2) inefficiency of a previous management principle oriented to the assignment of electricity and heat production volumes by higher management levels.

Privatization in the power engineering sector, which resulted in the organization of the Federal National Wholesale Electricity Market (FOREM), led to the formation of independent market entities instead of power systems: JSC-energo, JSC-power plants, etc. The subjects of the wholesale electricity market developed their own commercial interests aimed at profit maximization. Moreover, the previous criterion of fuel cost minimization was suitable only if the amount and operating mode of power and heat production were specified. In a competitive market, each entity aims to produce the amount of power and operate under the operating conditions that are beneficial for it $[42,43]$.

The leading principle of profit maximization is the criterion of control of the operation modes of HPPs at present [2,53-56]. This criteria is shown in Figure 1.

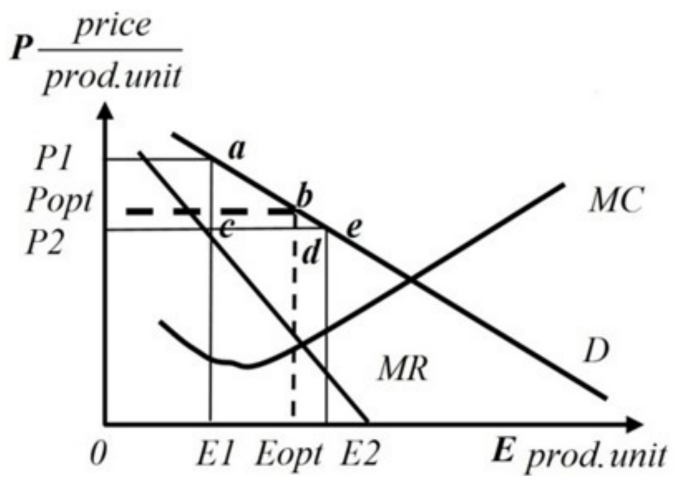

Figure 1. Assignment of the optimal operating modes of the station: $D$-energy demand curve for a typical season of the year; $E_{\text {opt }}$ - the most advantageous volume value for energy production; $P_{\text {opt }}$ - the cost of the most profitable volume of energy production; $M R$ - marginal revenue; $M C$ marginal cost. 
During the scientific research, the following general problems were solved: 1 . A patentoriented search for existing criteria for optimizing the modes of operation of mixed energy systems and the creation of a fundamentally new optimization criterion for managing the modes of operation of the water management complex based on a synergistic assessment of the cost of a hydro resource was performed. 2. The analysis of existing Russian and foreign methodologies of optimizing the operating modes of hydrothermal power systems was carried out. 3. A patent-oriented search was performed for previously developed methodologies devoted to the optimization of operating modes of the WUS. 4. A methodology for the synergistic evaluation of a hydro resource price was developed, taking into account the operating features of HPP functioning in the mixed power system. 5. An approach was developed to optimize HPP operating modes in the mixed power system. 6. A methodology was proposed for determining a hydro resource price for all the WUS participants based on determining a water price for HPP in modern conditions. 7. The developed principles and techniques were implemented in practice for a specific power facility. 8. A comparative analysis of the obtained results with previously developed methodologies was carried out.

The formulated problems and stages of their implementation are presented in Figure 2.

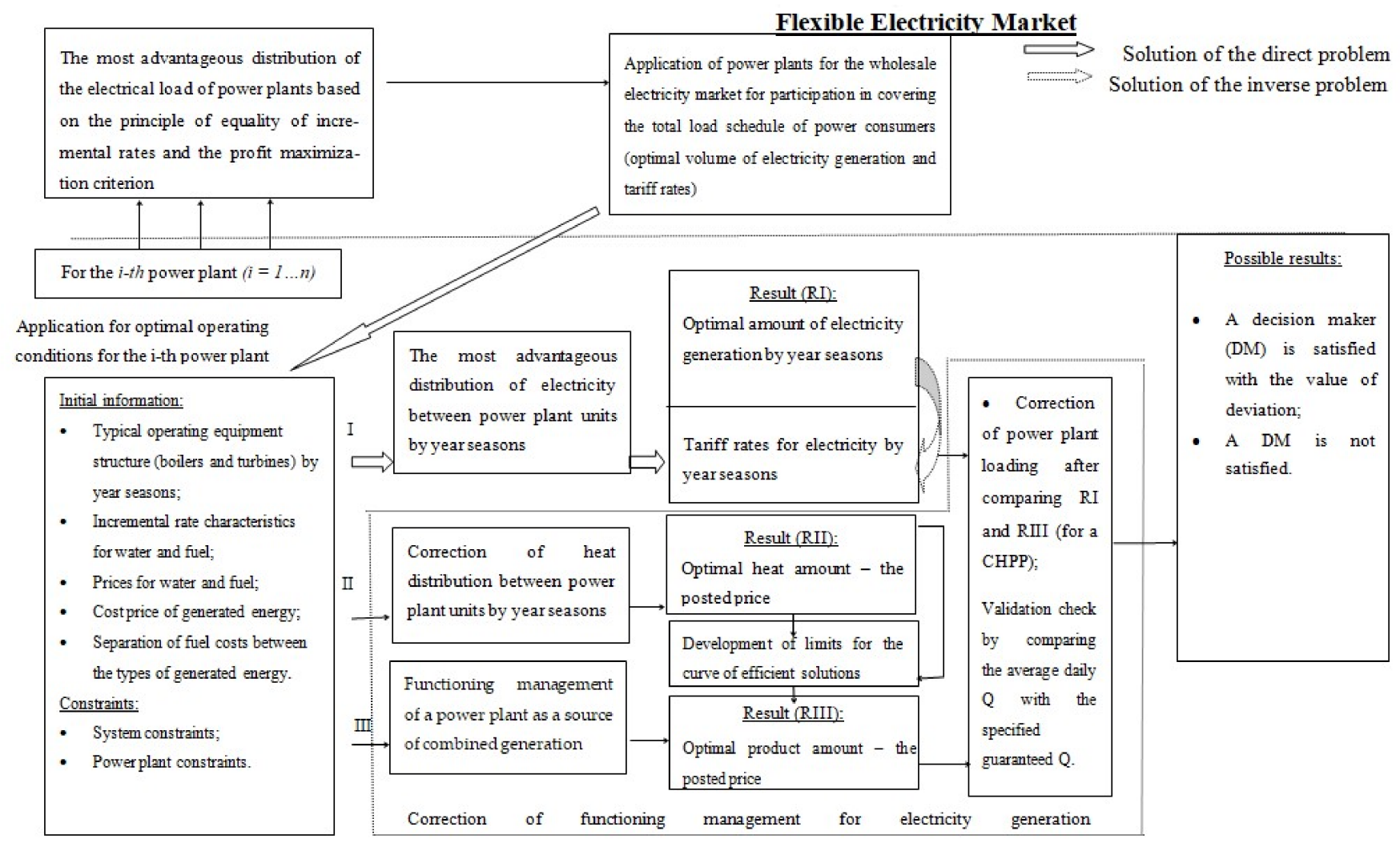

Figure 2. Block diagram for functioning management in the flexible market.

In modern conditions, when the number of harmful impacts on the environment is consistently increasing, improving the environmental situation is an important direction of investigations [44-47]. In this paper, it is proposed to increase the role of renewable energy sources using the example of the hydropower plant and carefully evaluate the possibilities of using a hydro resource without causing damage to nature by all the WUS participants [44].

The methodology developed by the authors for optimizing HPP operating modes in mixed power systems and based on the determination of a hydro resource price using the HPP operational features combines the theory of marginal utility and an optimization model [51,57]. Since power engineering is an infrastructure industry, the optimization of its operating modes will allow an optimizing operation of the entire WUS of the countries, 
which will allow implementing an energy-saving policy through a more careful attitude to natural resources.

Before developing a new optimization methodology, it is necessary to analyze in detail the previously developed optimization models $[5,6]$.

When considering the optimization conditions in the mixed power system, it is necessary to decide whether the head at the HPP will be constant or variable. It is usually taken permanently.

On this basis, the final optimization condition (1) is obtained $[5,6]$.

The coefficient $\lambda$ in this condition depends on the HPP parameters: on the head $(H)$ of the HPP and on the water flow rate $(Q)$ of the HPP, i.e., $\lambda=f(H, Q)$. Investigations show that the measure of efficiency for $\lambda$ increases with an increase in the HPP head. The coefficient $\lambda$ changes in the approximate range of [0.03...0.3]. Consequently, this coefficient $\lambda$ is used as a factor that allows the value of $q$ to determine the corresponding value of $b$. For this purpose, this coefficient is empirically chosen based on the condition of limiting water resources at HPPs. It should be noted that the number of iterations can exceed five. It is performed until condition (1) is fulfilled. These conditions seriously complicate the calculations. At the same time, the value of the pressure on the HPP is assumed to be constant.

The pressure on the HPP is assumed to be constant, which significantly rationalizes the process of solving the problem. The assumption of the constant HPP head significantly simplifies the solution algorithm. In this case, for the entire period of optimization, $1 \mathrm{~m}^{3}$ of hydro resources has almost the same energy.

Due to the fact that TPPs are simulated as generating sources with "unlimited energy resources" in optimization calculations, it is possible to reduce all TPPs into one equivalent TPP. In this case, all the technical constraints should be considered.

HPPs are characterized by "limited energy resources", therefore, the power values for the previous and subsequent time intervals are closely related to each other. Therefore, the HPP power at a given time depends on the power value in the previous time interval. Based on the above considerations, it is impossible to plot an equivalent characteristic of hydropower plants.

For hydrothermal EPS, the optimization problem is divided into two subtasks.

The first one is the optimization of long-term modes of the EPS.

In this problem, for the entire cycle of HPP regulation, the most favorable load distribution between power plants in the system is found, and the mode of using the water and energy resources of reservoirs is determined.

The calendar schedules of drawdown and filling of HPP reservoirs for all hydropower plants in the system are determined. Based on these calculations, hydro resources are regulated for short-term cycles. For example, if a hydropower plant has annual flow regulation, then resource (flow) constraints can be determined for a month, a week or a day.

The second one is the optimization of short-term operating modes.

At the same time, when optimizing mixed power systems, it is necessary to ensure the equality of the incremental water rate characteristics at the HPP (reduced to the TPP values) and the incremental fuel rate characteristics at the equivalent TPP for each time moment.

Certainly, the short-term and long-term HPP operating modes are closely related, but algorithmic and computational difficulties do not allow considering these problems in a single algorithm. The basis for such a division is also the difference in the completeness and reliability of the initial information. For a daily period, and sometimes for a weekly period, the information has sufficient reliability for practical purposes. It is possible to predict quite accurately the inflow of rivers, the system load, the unit commitment of power plants, etc. For long cycles, the information has a probabilistic or indefinite form. In addition, the combination of these problems involves a strong complication of optimization algorithms.

The condition of constancy of the pressure value is allowed.

The head change at the HPP can be caused by the variability of upstream and downstream levels during the optimization period. At dam HPPs with large reservoirs, the up- 
stream level changes little during a day, while the downstream level changes quite strongly. At diversion HPPs, the head can change by several meters due to a change of the head pond level.

The head change causes consequences, i.e., the influence of the HPP operating conditions at the current interval on subsequent time intervals. This complicates the optimization.

The optimization with the consideration of the head change due to the downstream can be carried out only when the program for calculating the unsteady conditions of flow rates and downstream levels is combined with the optimization program that causes great algorithmic difficulties. The structure of the complex of calculation programs involves the following components: forecasts (power system load schedules, hydrological forecasts of river flows); cascades (hydropower calculation of cascades); head changes (calculation of the unsteady mode for HPP downstreams); optimal load distribution in the power system.

For these purposes, it is proposed to use such software products as RASTR and Excel.

Most often the operating mode is calculated at constant (average per day) heads.

In this formulation, $\mathrm{b}$ and $\mathrm{q}$ have different dimensions. Therefore, the value of $\lambda$ is selected empirically. In this case, the limited hydro resources at the hydropower plant should also be taken into account. These conditions amount to a serious complication of the technique.

Taking into account all the above disadvantages of the existing model, it can be concluded that it is necessary to develop a fundamentally new optimization methodology for maintaining the operating modes of a hydrothermal power system which will be discussed in this article.

At the same time, it is proposed to use the theory of marginal utility as a basis, which, in combination with optimization models, will make it possible to develop the required methodology. With regard to our investigation, water and fuel are considered as products used for generation of the same amount of electricity [17-19].

Marginal utility can be determined using Equation (4):

$$
M U=\frac{\partial U}{\partial Q}
$$

where $M U$-marginal utility, $U$-utility function, $Q$ — quantity of good consumed.

The human attitude towards risk can be explained by utility analysis.

People often have to or can choose among alternatives that differ, in addition, by the degree of risk to which a person will be exposed.

Assume that we have a utility function at a given time, that is, we know the amount of utility which a given individual could gain from a given quantity of goods in the market. Then, we can derive a scale of preferences from this function. In this case, it is possible to consider any two goods, regardless of whether you prefer one to the other, or whether these goods are indifferent to you. If there are only two goods, then the scale of preferences can be expressed by a diagram of indifference curves.

The marginal substitution between two goods $X$ and $Y$ is determined by the slope of the indifference line for each particular subject.

With regard to our problem, we will consider the amount of water and fuel used to generate a given amount of electricity as products.

In the methodology developed by the authors, it is proposed to use their monetary equivalents, namely the marginal costs of water and fuel according to expressions (5) and (6), instead of the physical values of the characteristics of the relative increments of water consumption at HPPs and fuel at an equivalent TPP $[52,53]$. This will make it possible to more comprehensively and correctly reflect the physical picture when optimizing the operating modes of the mixed power system:

$$
\begin{gathered}
U_{B}=C_{B} B, \\
U_{Q}=C_{Q} Q,
\end{gathered}
$$


where $C_{B}$ and $C_{Q}$-declared sales price of fuel for TPPs and water for HPPs.

In more detail, expressions (2) and (3) can be rewritten as follows:

$$
\begin{aligned}
& b^{*}=C_{B} \frac{d B}{d Q}, \\
& q^{*}=C_{Q} \frac{d Q}{d N},
\end{aligned}
$$

The price of fuel differs according to the seasons of the year and depends on the grade of coal, its ash content, calorific value, moisture content, etc. and is a known value. The cost of a hydro resource, taking into account the operational characteristics of the operation of a hydropower plant in a mixed energy system, has not yet been determined, although attempts have been made.

As Russian and foreign experience shows, they use only a tax on water, including for flooded land, etc.

Therefore, it can be said that this work proposes a fundamentally new approach to the transition from a relative increase in fuel consumption at an equivalent TPP to a characteristic of relative increases in water consumption at a hydropower plant when optimizing operating modes of mixed power systems based on determining the cost of a hydro resource, which can be used when optimizing the water balance of the entire water-economic complex of the country. It is to this question that the work is devoted.

Thus, the condition for the most advantageous power diversity between stations in a mixed generation company based on a new concept can be represented in another form (9). Moreover, it should be noted that since only generating sources are considered in this article, power losses in networks are neglected. Under the conditions according to the methodology from [58], the parameters $b^{*}$ and $q^{*}$ are determined by (7) and (8).

The characteristic of the marginal costs for hydropower plants imposed restrictions on the through put of the turbine and the power of the generator, as well as on the run off that can be used from the reservoir for a certain period $\mathrm{T}$.

We will create an empirical model for estimating the cost of water for a hydroelectric power station operating as part of a generating one, we will construct a mathematical model. Any mathematical model consists of five equations, which we will consider below.

The first is the goal equation:

$$
\frac{1-\sigma}{b}=\frac{1-\sigma}{q} \text { at } U=\text { const },
$$

where $U$ is the indifference curve.

To find the values of $b$ and $q$ in expression (9), used in constructing the indifference curve, it is necessary to use the value of the guaranteed power $\left(N_{\text {guar }}\right)$, which is obtained from the results of the water-energy calculation. The value of the guaranteed capacity must correspond to the calculated capacity of the year.

After that, for the found value of $N_{\text {guar }}$, the value of the water flow rate $Q$ is found

$$
N_{\text {GUAR }}^{A}\left(E_{\text {month }}\right) \rightarrow Q
$$

at $N_{G U A R}=$ const.

Then the value of the relative increase in the water flow rate $(q)$ is determined by the differential characteristic of the water flow rate.

$$
q=\frac{d Q_{H P P}}{d N_{\text {guar }}} \cdot Q_{H P P} \geq Q_{\text {guar }} .
$$

Equations of balance constraints can be represented by the expression (11):

$$
N_{S}^{A}=N_{G U A R}^{A}+N_{T P P}^{A}
$$


Next, you need to build a constraint equation. This will reflect the fulfillment of such a requirement as the observance of the energy balance of the energy system.

$$
B=f\left(P_{T P P}\right), Q_{H P P}=f\left(P_{H P P}, H_{H P P}\right) .
$$

Then, from Equation (12), the power value of the equivalent TPP is determined

$$
P_{S}^{A}-P_{G U A R}^{A}=P_{T P P}^{A}
$$

After that, according to the characteristic of the relative increase in fuel consumption at an equivalent TPP, the corresponding value of its relative increase is found.

$$
b=\frac{d B}{d P}_{T P P}
$$

At the same time, an important note is the fact that the current values of the relative increases in water consumption at HPPs and fuel at TPPs were divided by the average values of the relative increases in water and fuel consumption, respectively, in order to obtain graphs of the relative consumption of energy resources at the plants.

Further, according to the obtained values, a curve of marginal usefulness or indifference was constructed (Figure 3).

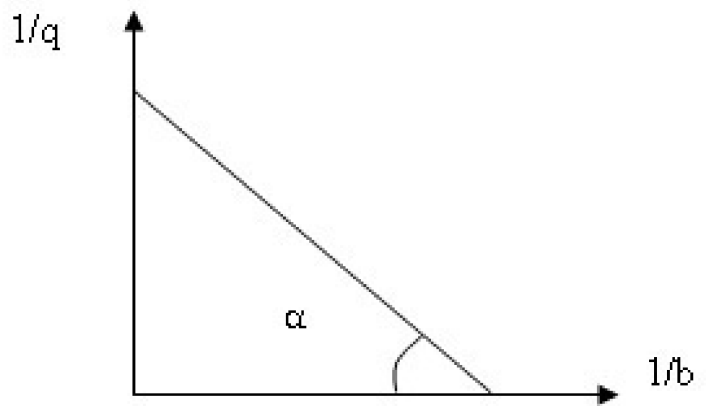

Figure 3. Indifference curve graph.

The authors of the developed technique obtained a new rule for the transition from the values of the relative increase in water consumption to the relative increase in fuel consumption: in this case, the value of the relative increase in water consumption at HPPs $\mathrm{q}^{\prime}$, which lies on the indifference graph (see Figure 3), will be equal to the corresponding indicator of the differential characteristic at TPPs $b^{\prime}$, which belongs to the same indifference curve.

When solving optimization problems for hydrothermal power systems consisting of hydropower plants and thermal power plants, this is a clear advantage of the technique, since it significantly reduces the computer time for the implementation of the task, replacing five iterations with one action.

It should also be noted that the power indicators for a certain hour of the daily load schedule belong to this indifference curve within a certain month [52,53].

Using the values of $N_{\text {guar }}$ for hydropower plants and the indicator of the total power of the generation company for a certain moment, we find the power of an equivalent $\mathrm{CHP}$ based on the characteristics of equality of relative increases in fuel consumption (see Figures 4-6). 


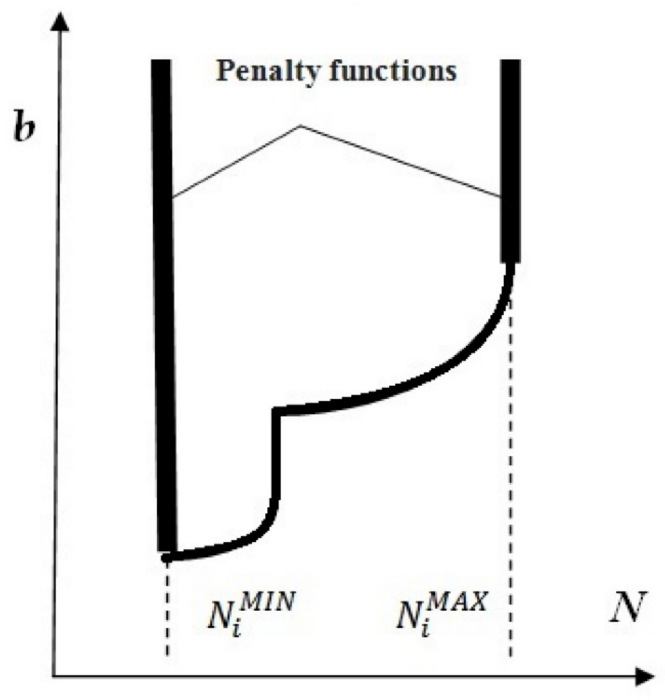

Figure 4. Penalty functions for TPP.

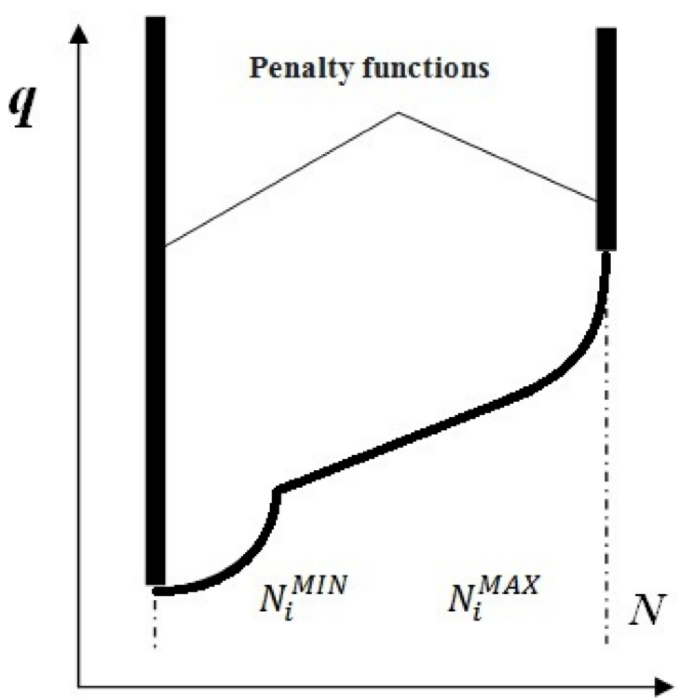

Figure 5. Penalty functions for HPP.

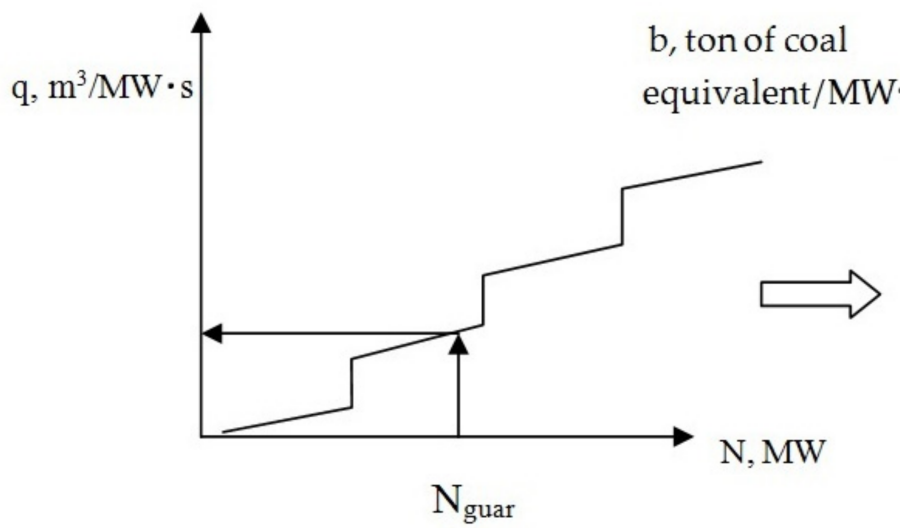

(a)

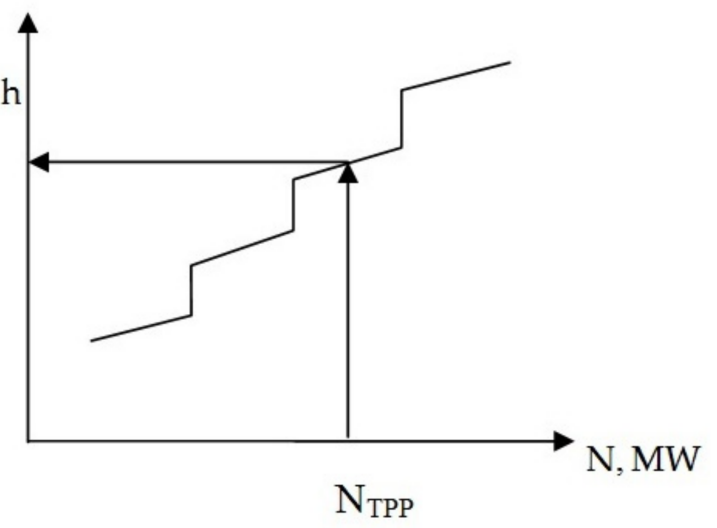

(b)

Figure 6. Characteristics of the relative increase in water consumption at HPP (a) and fuel at an equivalent TPP (b). 
4. It is also necessary to consider the following constraints:

$$
\begin{aligned}
& N_{T P P} \min \leq N_{T P P} \leq N_{T P P} \max , \\
& N_{H P P} \text { min } \leq N_{H P P} \leq N_{H P P} \max ,
\end{aligned}
$$

To take into account the restrictions of the form $N_{i}^{M A X} \geq N_{i} \geq N_{i}^{M I N}$, the imposition of penalties on the zones of undesirable work is used, i.e., for the maximum $N_{i}^{M A X}$ and minimum $N_{i}^{M I N}$ power plants (Figures 4 and 5). The same constraints apply to the marginal costs of fuel and water.

5. After that, we construct an optimization equation for the equality of marginal costs to marginal revenue according to the criterion of profit maximization. With the aim of constructing a curve of marginal costs, the cost of a hydro-resource is determined, taking into account the regime characteristics of a hydropower plant and the forced heating mode of an equivalent TPP, using the criterion of environmental and economic efficiency proposed by the authors.

To determine the cost of a hydro resource at a hydropower plant, the following sequence of actions is used.

When moving from physical indicators of the relative increase in fuel consumption at TPPs and water at HPPs on the indifference curve to a similar graph in marginal costs, it must be said that the angle of inclination of the tangent to the graph $(\alpha)$ will be the similar to that shown in Figure 3.

Further, on the basis of the indifference curve (see Figure 7), using marginal costs, we find the cost of a hydro resource at a hydropower plant operating in a hydrothermal energy system.

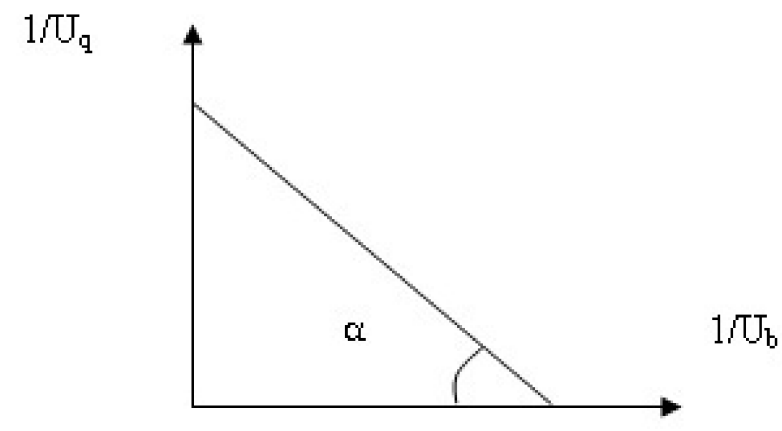

Figure 7. The marginal cost indifference curve.

The cost of a hydro resource for a hydropower plant is determined as follows:

$$
U_{q}=\operatorname{ts} * q, \operatorname{tg} \alpha=\frac{\frac{1}{q}}{\frac{1}{b}}, p_{w}=\operatorname{tg} \alpha * \frac{U_{B}}{p_{f}} .
$$

Then the marginal costs for hydropower plants are determined as follows:

$$
M C=p_{w} * q
$$

To find the optimal values of the generated power for the seasons of the year, it is necessary to solve a system of equations describing the marginal costs and marginal income of the station:

$$
N_{o p t}=E_{o p t} / t_{\text {month }}
$$

where $t_{\text {month }}$ is the average number of hours of equipment operation per month $(720 \mathrm{~h})$.

There is no need to check the equality of the given flow rate with the average daily water flow rate at the hydropower plant. 
Moreover, the calculation is performed in one operation instead of five or more iterations according to the existing method of equality of the relative increments of fuel consumption, which significantly improves the convergence of the method and saves machine time. This is an important advantage of the proposed technique.

Moreover, when switching to monetary units, when constructing the characteristics of the relative increase in water consumption at HPPs and fuel at an equivalent TPP, a check of the form $\lambda=$ const is not required [53].

And as one of the most important advantages of the method, it can be noted that it becomes possible to realistically determine the cost of a hydro resource, taking into account the regime characteristics of hydropower plant, in order to comply with the conditions for the energy balance of generating companies [53-57].

All this makes the methodology developed by the authors competitive and adequate to the requirements of a flexible energy market, when the role of renewable energy sources increases, which makes it possible to improve the environmental situation in the world as a whole, as well as to solve important energy saving problems. Moreover, it is energy efficient from the point of view of managing the modes of the hydropower plant of the entire water-economic complex (WEC).

\section{A Creation of a Mathematical Model for Determining the Price of Water Utilization System (WUS)}

Formation of the structure of the water management complex (WHC) is one of the complex pre-project tasks. Its solution begins with the establishment of the boundaries of the basin under consideration and the choice of those main sectors of the national economy that need to be provided with water. WHC is also created in order to rationally, at minimal cost to society, use water resources and protect them from depletion and pollution.

The water management balance (WHB) is one of the main parts of the scheme for the integrated use and protection of water resources in the river basin. It makes it possible to judge the possibility of meeting the water demand of prospective participants in the water management complex. Water management balance is the ratio of the inflow, flow and accumulation of water for a river basin or any water body for a certain period of time.

On the other hand, availability of water for various sectors of the national economy is influenced by a number of climatological factors, such as, for example, the water content of a given year (low-water, medium-water, or high-water), as well as the operating conditions of an HPP. Since the operating mode of an HPP depends on climatological conditions, it is widely accepted that there are three characteristic operating conditions: high water period, low water period and operation with natural river flow. The design was based on the operational characteristics of the PL-30/877-V-930 type turbine (see Figure 8). This characteristic is based on the results of field tests carried out at the station for a turbine of the indicated type. It links the values of three parameters: head, power and efficiency isolines. All calculations were carried out for the value of the design head.

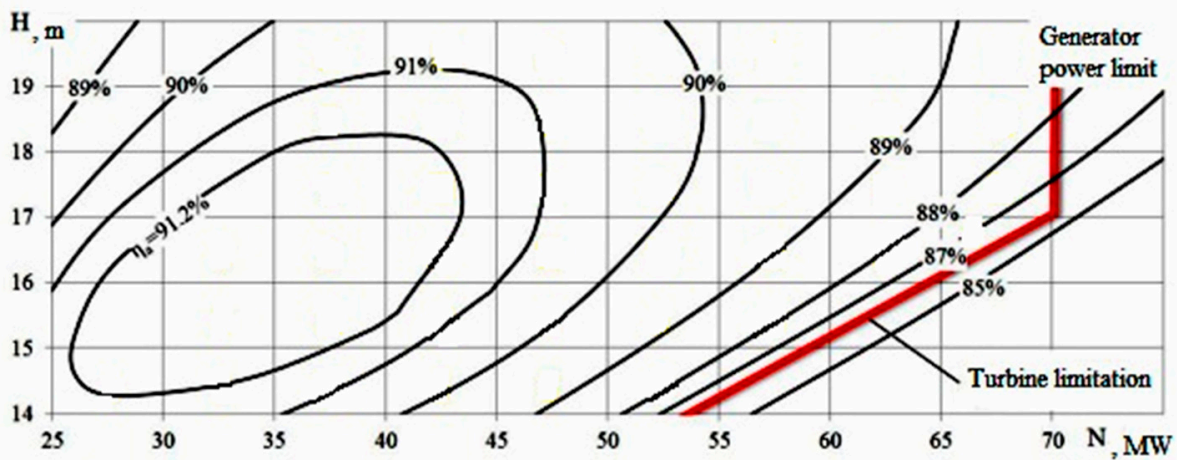

Figure 8. Operational characteristics of the PL-30/877-V-930 type turbine. 
The number of hydro units was specified, being the initial information: for a highwater period-7 hydro units, for a low-water period- 2 hydro units, for operation with natural river flow -4 hydro units.

The initial data includes the operational characteristic of a hydro unit, which is the efficiency isolines in the "head-power" coordinates. To plot the operating characteristic of a hydro unit, it is necessary to intersect the operational characteristic by isolines $H=$ const and project the intersection points of the secants with the efficiency isolines into the $X$-axis to determine the values $N_{h u}$.

The flow rate characteristics of a hydro unit $Q=f(N, H)$ at $H=$ const can be plotted on the basis of operating characteristics using the following dependence [5]:

$$
Q=\frac{N \cdot 10^{-3}}{9.81 \cdot H \cdot \eta}
$$

where $N$-HPP power, $H$-head value, $\eta$-efficiency value.

Plotting of the operating characteristic of the HPP with lines of hydro unit connection is considered for the case when the operating characteristics of all hydro units of the HPP are the same. Then, the operating characteristic of the HPP with one hydro unit connected is the operating characteristic of this unit. When $\mathrm{z}$ units are connected, coordinates of the HPP characteristic points along the $X$-axis increase by $z$ times. The intersection points of the HPP operating characteristic when changing the number of operating hydro units are called connection points.

The initial data for constructing the HPP flow rate characteristic is the flow rate characteristic of one hydro unit:

$$
Q_{h u}=Q_{h u}\left(N_{h u}, H\right)
$$

It is necessary to plot $Q_{H P P}=Q\left(N_{H P P}, H\right)$.

For example, Figure 9 illustrates the flow rate characteristic of the Novosibirsk HPP for the head of $17.5 \mathrm{~m}$.

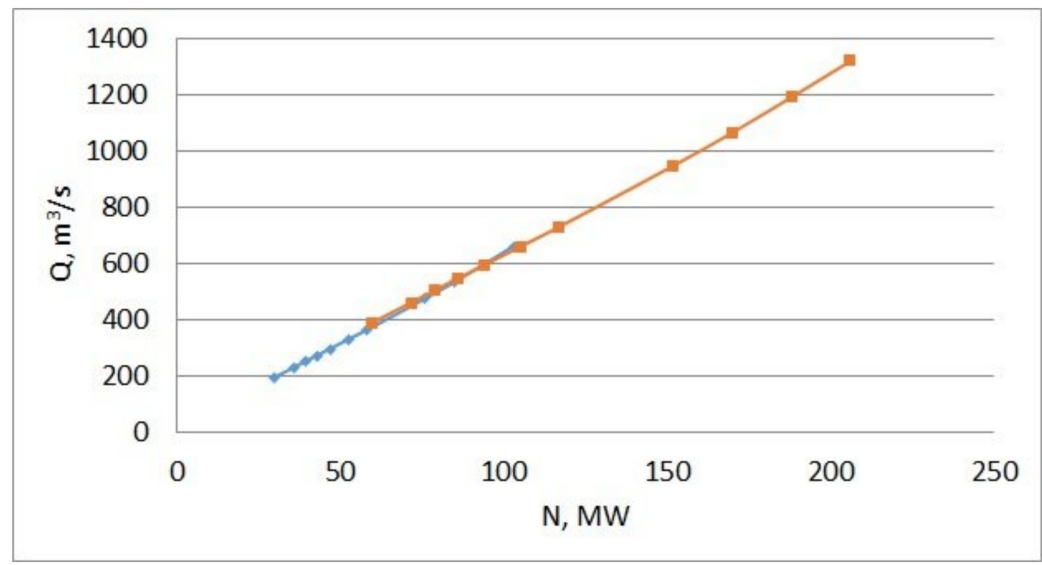

Figure 9. Flow rate characteristic of the HPP with two turbines PL-30/877-V-930 operated with the head of $H=17.5 \mathrm{~m}$.

The standards establish water consumption norms for each branch of the WHC Wi (Formulas (23)-(27)). Knowing these two above-given parameters, it is possible to determine the probabilities of water supply of the $i$-th industry:

$$
P_{i}=Q_{i} / W_{i}, \%
$$

It should be noted that the price of water will be different depending on the water content of the year. 
The technique for finding the deviation of the volume of water consumption by each industry from the norm is shown in [58].

To search for the monetary equivalent of such a deviation, the authors proposed to use the graphs in Figure 10.

$1 / \Delta Q_{\mathrm{i}}$

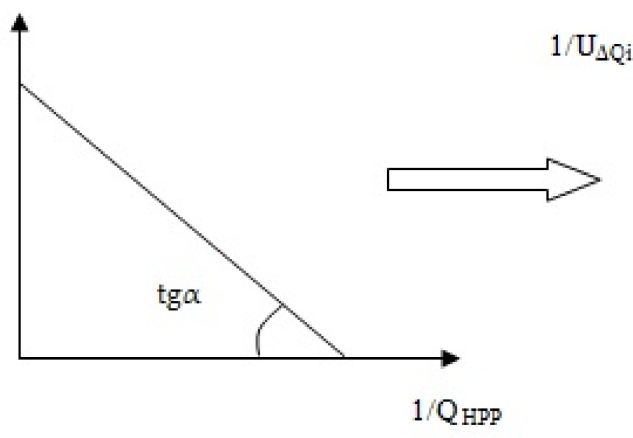

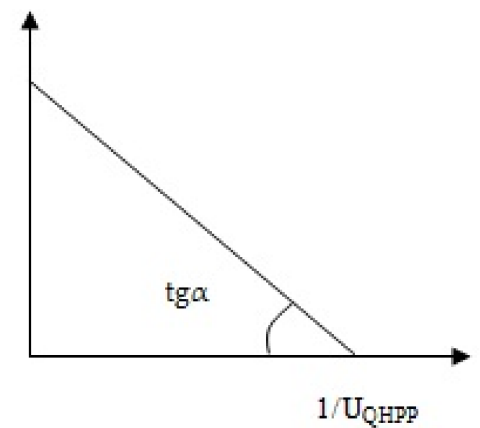

Figure 10. Indifference curves for determining a hydro resource price for the $i$-th branch of the national economy.

The monetary equivalent of the deviation value can be found using the following formula:

$$
U_{\Delta Q_{i}}=p_{\Delta Q_{i}} * \Delta Q_{i}, \operatorname{tg} \alpha=\frac{\frac{1}{\Delta Q_{i}}}{\frac{1}{Q_{H P P}}}, t s_{\Delta Q_{i}}=\frac{p_{H P P} * Q_{H P P}}{\operatorname{tg} \alpha * \Delta Q_{i}}
$$

Then, a hydro resource price for the $i$-th branch of the national economy will be calculated by the expression:

$$
p_{i b r}=p_{H P P}+p_{\triangle Q_{i}} .
$$

For making reasonable management decisions, it is necessary to use the method of binary compromises. In this case, the solution of the multidimensional problem is transferred to the plane. The essence of the binary search method is that each of two randomly taken branches is compared with a branch, which is taken as the base branch, according to a certain parameter. As such, for this study, water flow rate at the $\operatorname{HPP}\left(\mathrm{Q}, \mathrm{m}^{3} / \mathrm{s}\right)$ is considered. Then, the branches are compared with each other, and a hydro resource price is substantiated for each of them and for the entire WUS.

When developing a mathematical model to solve the problem, it is necessary to select the criteria of WUS functioning management. As such, we use the water flow rate $\left(\mathrm{Q}, \mathrm{m}^{3} / \mathrm{s}\right)$ representing the ecological and economic efficiency criterion and conforming to the minimax principle, as well as the reliability criterion, which is represented by a special physical parameter for each of the branches and determined according to the max-min principle.

Therefore, a pairwise comparison is conducted for each branch of the national economy with the HPP using the Pareto optimal set. At the same time, the aim of this investigation is to check the possibility of improving the water balance by the criterion of energy efficiency for the entire national economy.

In addition, it is necessary to distinguish mutually exclusive branches (HPP, fishery, shipping, agriculture) and mutually complementary branches (HPP, industry, households). The branches that will be interesting are only those that have a contradiction with each other, i.e., mutually exclusive branches. In this case, there is a multicriteria problem of meeting the needs of conflicting water consumers. This means that meeting the water needs of one of them leads to a change in the water regime for another consumer. At the same time, it is necessary to achieve an optimal water supply regime for the entire water utilization system.

Thus, a multicriteria problem is a process of simultaneous optimization of two or more conflicting objective functions in a given domain of definition. 
To solve the problem on separate individual (local) Pareto optimal sets, it is necessary to compare each mutually exclusive branch of the national economy with the HPP according to two mutually exclusive criteria: reliability and ecological compatibility and economy (Figure 11). This is facilitated by the fact that there are only three such branches (agriculture, shipping and fishery).

$\mathrm{Q}, \mathrm{m}^{3} / \mathrm{s}$, ecological

compatibility and economy

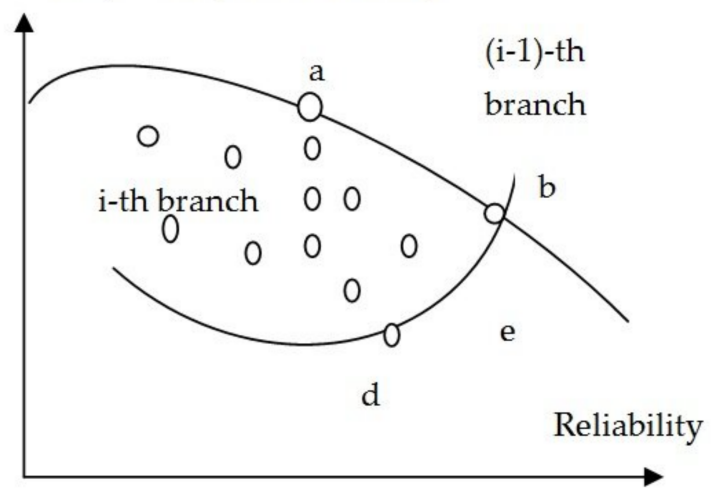

Figure 11. Pareto optimal set for fishery (shipping, agriculture) and the HPP basic point.

Consider, for example, HPP and fishery.

Moreover, it should be noted that the curve ab would be optimal for an HPP from the perspective of electricity generation, while fishing (shipping and agriculture) will have the curve de.

In addition, vice versa, when the curve mn is optimal for fishery (shipping and agriculture) from the perspective of ensuring guaranteed production output, then the HPP will have the $\mathrm{kl}$ curve (Figure 12).

$$
\begin{aligned}
& \mathrm{Q}, \mathrm{m}^{3} / \mathrm{s} \text {, ecological } \\
& \text { compatibility and economy }
\end{aligned}
$$

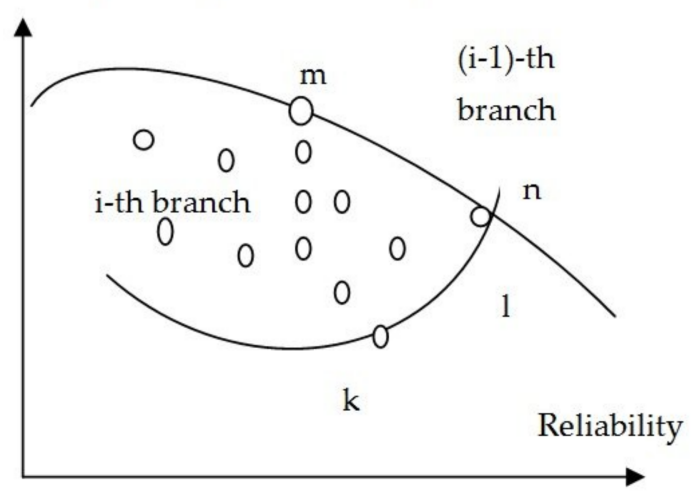

Figure 12. Pareto optimal set for fishing (shipping, agriculture) and the HPP basic point.

Therefore, in this case, the area mnkl is obtained.

Then, crossing the areas abde and mnkl, we can get an area of compromise solutions for mutually exclusive branches. Based on this area, a decision maker proposes a solution using their own intuition and experience (Figure 13). 
$\mathrm{Q}, \mathrm{m}^{3} / \mathrm{s}$, ecological

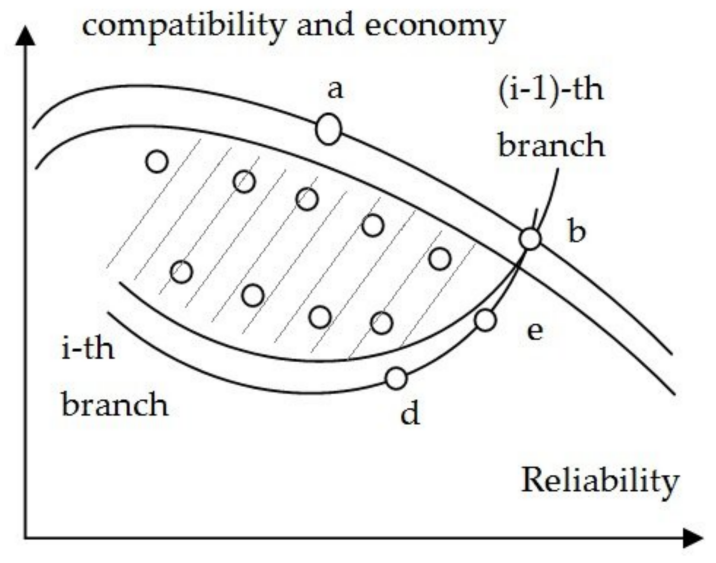

Figure 13. A compromise solution for mutually exclusive branches.

Consider the implementation of the proposed idea using the example of shipping and the HPP. In this case, the guaranteed depth (width) of the navigable pass can be taken as a reliability criterion. This is the smallest depth (width) of the navigable pass established on a section of the navigable route at the design water level. (Russian National Standard GOST 26775-97. Clearances of navigable bridge spans in the inland waterways. Norms and technical requirements).

Thus, to compare fishing and the HPP on the same Pareto optimal set, it is necessary to scale the parameters according to the reliability criterion for each of the branches and convert them into relative units. For the HPP, such a parameter will be the guaranteed power, and for fishing it will be the commercial return of fish.

For example, consider the volume of regulating releases:

Per year:

$$
W_{\text {year }}^{\text {reg }}=Q_{\text {reg }} * T, \mathrm{~m}^{3},
$$

where $Q_{\text {reg }}$-rate of scheduled regulating releases, $\mathrm{m}^{3} / \mathrm{s} ; T$-year duration in seconds.

Per month:

$$
W_{m}^{r e g}=\frac{W_{\text {year }}^{r e g}}{12}, \mathrm{~m}^{3}
$$

The volume of waste water dilution:

$$
W_{w w d}=K_{d} * K_{r} * W_{\text {cons }}, \mathrm{m}^{3}
$$

where $K_{d}$-rate of waste water dilution; $K_{r}$-return rate; $W_{\text {cons }}$-volume of water consumption, $\mathrm{m}^{3}$.

In this case, the available resources are calculated by the formula:

$$
W=Q_{t} * t * k,
$$

where $Q_{t}$-water flow rate per a considered period, $\mathrm{m}^{3} / \mathrm{s} ; t$-month duration in seconds, $\mathrm{s} ; k=0.95 \ldots 0.97$-the coefficient that takes into account the loss of water for evaporation and infiltration.

In this case, the requirement of complying with the water balance should be met. Then, using the indifference curve, it is easy to move from the water consumption by each specific branch to the determination of a hydro resource price for each branch of the national economy on the basis of expressions (21) and (22).

Therefore, there is reference data on electricity consumption per product unit output for each branch of the industry, $m_{i}, \%$. At the same time, knowing the production volume 
of the branch $\left(V_{i}\right)$, it is possible to determine the volume of electricity consumption by the $i$-th branch:

$$
V_{i} * m_{i}=N_{i}
$$

Therefore, the energy demand is calculated based on statistical observations of its specific average annual consumption for each type of the end product $\mathrm{m}_{\mathrm{i}}$, measured in gigajoules per production unit.

\section{Practical Implementation of the Proposed Methods and an Analysis of the Results Obtained}

Let us give a practical implementation of the developed methodology using the example of Novosibirsk HPPs and an equivalent TPP, consisting of NTEP-2, NTEP-3, NTEP4 and NTEP-5 for each season of the year, since energy consumption has a pronounced seasonal character.

It should be noted the initial data was obtained from the water-power calculation of a low-water year (calendar year-1912 with an estimated availability of $92 \%$ ).

On its basis, the operating characteristic of the Novosibirsk HPP was calculated for three head levels (high-water- $14.05 \mathrm{~m}$, low-water- $17.5 \mathrm{~m}$, operation with natural river flow-17.9 $\mathrm{m}$ ) by drawing a constant line of head on the operational characteristic and determining the intersection points with the lines of turbine efficiency [52,53].

It should be noted that the heads were obtained as an arithmetic mean taken for the following characteristic seasons of the year: high-water period (V, VI, VII, VIII months), low-water period (I, II, III, IV months) and operation with natural river flow (IX, X, XI, XII months).

Structurally, the Novosibirsk HPP is a low-pressure run-of-river hydropower plant (the HPP building is part of the pressure front) (Table 1). The turbines are rotary vane, the design head is $17 \mathrm{~m}$ and the impeller diameter is $8 \mathrm{~m}$. The throughput of the entire spillway dam is $9200 \mathrm{~m}^{3} / \mathrm{s}$ (at the NSP), at the FPU- $13,400 \mathrm{~m}^{3 /} \mathrm{s}$.

Table 1. Power and energy characteristics of the Novosibirsk HPP.

\begin{tabular}{lc}
\hline Number of units & 7 \\
\hline Installed power at design head, MW & 490 \\
\hline Design average annual output, million $\mathrm{kWh}$ & 1687 \\
\hline
\end{tabular}

As mentioned above, in order to optimize the operating modes of the hydropower plant according to the seasons of the year, it is necessary to determine the cost of the hydro resource, taking into account the operating characteristics of the Novosibirsk hydropower plant.

As an example, consider the determination of the cost of a water resource for January, which refers to the low-water period.

After the main fuel consumption characteristic of HPP was built for the first month on the basis of the operational characteristics of the Novosibirsk hydropower plant (see Figure 8) and the flow characteristics (see Figure 9), we need to proceed to the calculation of the cost of the hydro resource as the next step. For this, according to the main fuel consumption characteristic graph in Figure 14, it is necessary to determine the value of the relative increase $\mathrm{q}$, which corresponds to the guaranteed capacity $N_{G U A R}$ for the calculated month. To determine the value of $\mathrm{q}$, draw an additional line of guaranteed power before crossing the graph, and after determining the value of the relative gain from the point of intersection, lower the perpendicular to the ordinate axis and obtain the desired value. 


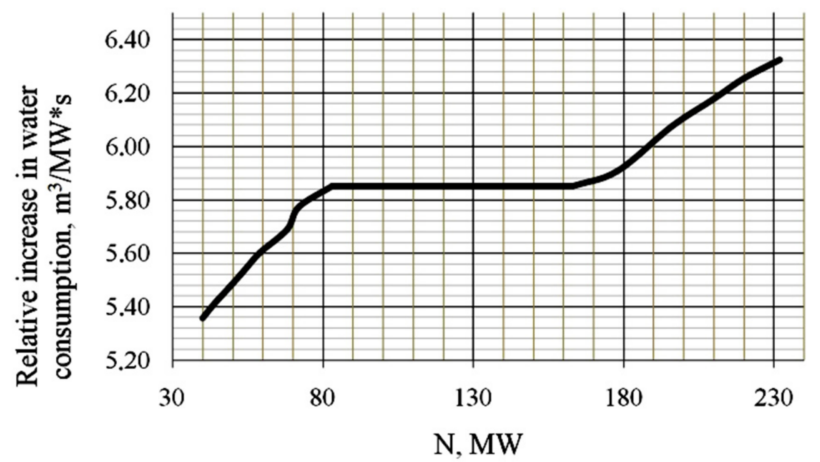

Figure 14. TPP main fuel consumption characteristic for January.

For the first month for $N_{\text {guar }}=64 \mathrm{MW}$, the corresponding value of $q$ is:

$$
q_{\text {january }}^{*}=5.64 \frac{\mathrm{m}^{3}}{\mathrm{MW} * \mathrm{~s}} \text {. }
$$

From the initial data for the balance of the power system, we determine to be $N_{\text {eqw }}$ TPPthe power of electricity in MW at the TP [54].

Using the formula for the balance of the EES (12), we determine the values of hourly power generation equivalent to the TPP. For example, for the first hour it will be equal to $N$ $N_{E E S}-N_{G U A R ~ H P P}=1635.414-64=1571.414 \mathrm{MW}$. Then a similar calculation is carried out for each hour of the day.

After that, the average daily value $N_{\text {eqw TPP av }}=2017.12 \mathrm{MW} \mathrm{MW}$ is determined as the arithmetic mean of the values for all values for each hour, and the resulting value is plotted on the graph to determine the value relative to the increase in fuel consumption $b_{\text {january }}^{*}$ for $N_{\text {ewq TPP }}$ of a given month. Next, we proceed to the determination of the relative increase for an equivalent TPP according to the original schedule of the TPP main fuel consumption characteristic for the mid-autumn period, shown in Figure 15.

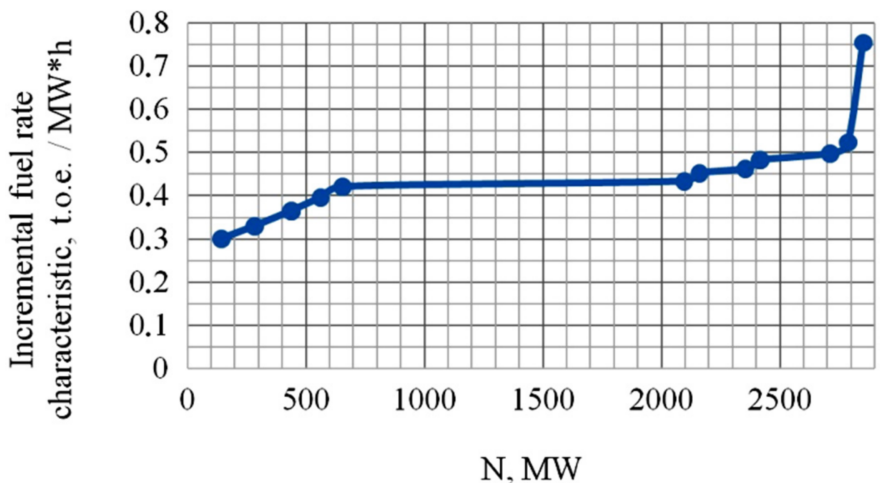

Figure 15. TPP main fuel consumption characteristic for the low-water period.

According to the graph, we find the value of the relative increase for $N_{\text {eqw TPP av }}=2017.12 \mathrm{MW}$, then we get:

$$
b_{\text {january }}^{*}=0.435 \frac{\text { toe }}{\mathrm{MW} * \mathrm{~h}} .
$$

At the same time, according to the rules for constructing the indifference curve, it is necessary to take the value sin verse of $b$ and $q$, i.e., $1 / b$ and $1 / q$ and set a side, respectively, along the abscissa and ordinate axes, and then connect the setpoints with a line, which will be called the indifference curve, shown in Figure 3. Moreover, it should be noted that from the physical parameters $1 / q,\left[\mathrm{~s}^{*} \mathrm{~kW} / \mathrm{m}^{3}\right]$ and $1 / b,[\mathrm{kWh} /$ ton of coal equivalent], it is necessary to move to relative units, since this will allow us to compare on one graph 
the indifference curve constructed in relative units depending on the multi-dimensional quantities $b$ and $q$. The values inverse to the values of the relative increments of the HPP and the equivalent TPP for the first month will be equal to:

$$
\frac{1}{q_{\text {january }}^{*}}=\frac{1}{5.64}=0.177 \mathrm{uv}, \frac{1}{b_{\text {january }}^{*}}=\frac{1}{0.435}=2.299 \mathrm{uv}
$$

Based on the calculated data, we will construct the indifference curve shown in Figure 16.

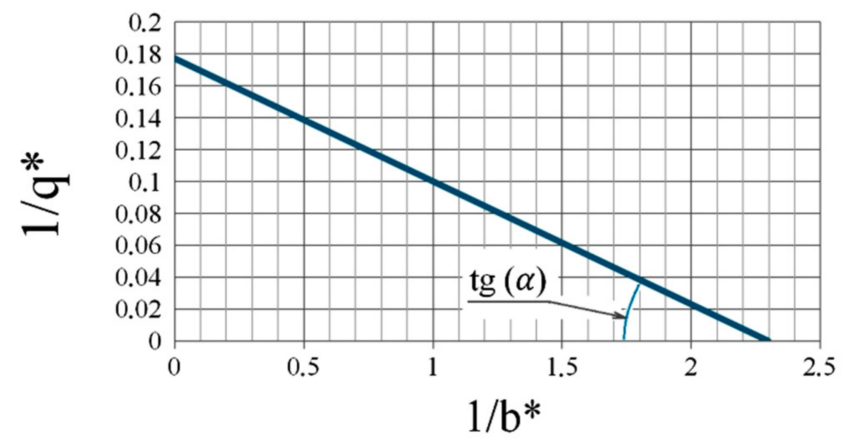

Figure 16. The indifference curve for consumption for January.

The value of $\tan (\alpha)$ for characterizing the marginal cost of water remains unchanged compared to the indifference curve for water consumption.

From here it is possible to determine the price of water for HPPs, guided by the following graph shown in Figure 17.

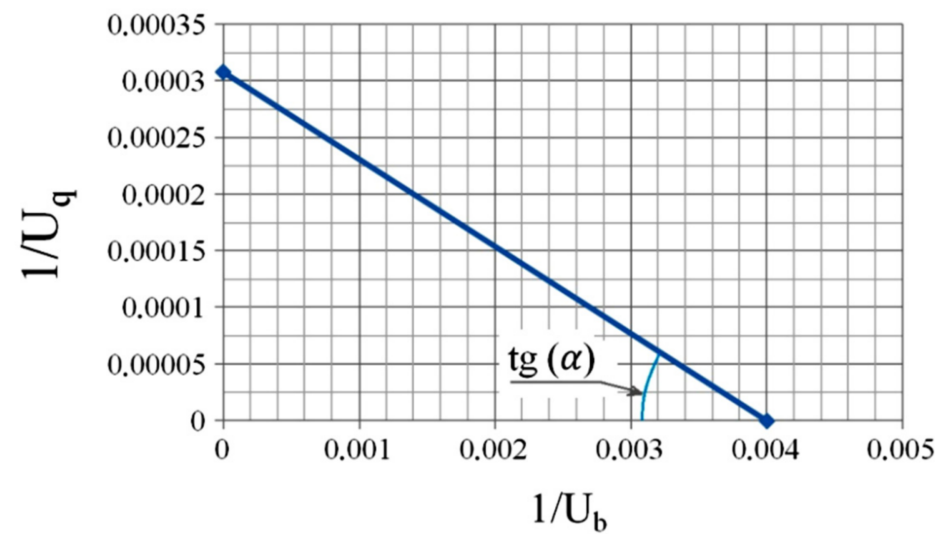

Figure 17. The indifference curve for marginal costs for January.

Define $\operatorname{tg}(\alpha)$ as: $\operatorname{tg}(\alpha)=\frac{\frac{1}{\bar{q}_{\text {january }}^{*}}}{\overline{b_{\text {january }}^{*}}}=\frac{0.177}{2.299}=0.077$ Then, similarly, we will proceed to marginal costs according to formula (16) and find the cost of hydro resources, taking into account the regime features of the HPP. To do this, it is necessary to determine the value of marginal costs at an equivalent TPP (see Figure 18). 


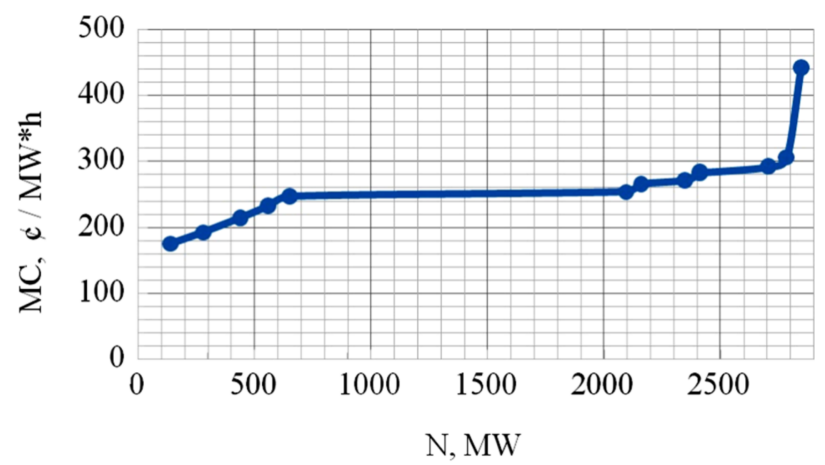

Figure 18. Characteristic of the marginal costs of the equivalent TPP for the winter period.

Then we get: $U_{b}$ january $=333.33 \frac{\mathrm{C} /}{\mathrm{MW} * \mathrm{~h}}$. Next, using the Formula (16), we determine the cost of water resources for the month of January, substituting all known calculated values, then we get:

$$
\bigsqcup_{\text {water }}=\frac{U_{b \text { january }}}{\operatorname{tg}(\alpha) * q_{\text {january }}^{*}}=\frac{333.33}{0.077 * 5.64 * 3600}=0.213 \frac{\mathrm{C} /}{\mathrm{m}^{3}} .
$$

The results of the calculations to determine the cost of a hydro resource according to the methodology developed by the authors, taking into account the regime characteristics of the HPP for each month of the year, are shown in Table 2.

Table 2. Hydro resource price for each period of the year with the HPP operating features taken into account.

\begin{tabular}{cc}
\hline Period & Drawdown \\
\hline Month & Hydro resource price, $p_{\text {water }}, \phi / \mathrm{m}^{3} / \mathrm{s}$ \\
1 & 0.212856 \\
2 & 0.212212 \\
3 & 0.211143 \\
4 & 0.211276 \\
Period & Filling \\
Month & Hydro resource price, $p_{\text {water }}, \propto / \mathrm{m}^{3} / \mathrm{s}$ \\
5 & 0.127127 \\
6 & 0.127407 \\
7 & 0.127407 \\
8 & 0.131687 \\
Period & Natural afflux \\
Month & Hydro resource price, $p_{\text {water }}, \propto / \mathrm{m}^{3} / \mathrm{s}$ \\
9 & 0.151791 \\
10 & 0.149911 \\
11 & 0.165844 \\
12 & 0.161333 \\
\hline
\end{tabular}

The implementation of the approach proposed by the authors at the NGPP gave the following results for the period of drawdown, filling and household drain. As shown in Table 1 , the price of water for the flood season is $p_{\text {water }(\text { flood season })}=0.211 \mathrm{C} / / \mathrm{m}^{3} / \mathrm{s}$, the average price in the low-water period is $p_{\text {water }(\text { low-water })}=0.1284 \mathrm{C} / / \mathrm{m}^{3} / \mathrm{s}$ and the average price in the natural afflux period is $p_{\text {water (natural afflux) }}=0.159 \mathrm{C} / / \mathrm{m}^{3} / \mathrm{s}$.

To check the correctness of the methodology proposed by the authors, it is necessary to compare the cost of fuel at an equivalent TPP with the cost of a hydraulic resource at an equivalent HPP. In this case, we find that for the period of operation, the cost of water at the Novosibirsk HPP is $0.211 \not / \mathrm{m}^{3} / \mathrm{s}$ or $0.211 \times 3600=759.6 \not / \mathrm{m}^{3}$, which can be correlated 
with the price of 1 ton of brown coal, which is $920-1307 \not \subset$ per ton, depending on the season in question.

The calculated values allow comparing them with the price of power-generating fuel at CHPPs (for example, for brown coal it equals 920-1307 $\not$ per ton, and for Kuznetsk coal it is about $1533 \not$ per ton). The calculated values of the water price at the Novosibirsk HPP are less than the price of power-generating fuel at CHPPs that illustrates the efficiency of the applied calculation method. This will allow loading a more economical hydropower plant instead of an alternative thermal power plant in a certain period.

The indicators for the operating period at the NHPP will be $0.211 \times 3600=759.6 \not / \mathrm{m}^{3}$. This figure is two times less than the cost of 1 ton of Kuznetsk coal, equal to $1600 \not$ per ton. That speaks to the correctness this method, since it makes it possible to load a more environmentally friendly and economical hydropower plant instead of an equivalent thermal power plant.

Then, we will optimize the operation modes of the HPP as part of a mixed power system based on the proposed environmental and economic criterion. According to condition (17), we obtain a characteristic of marginal costs. For example, Figures 18 and 19 show the marginal cost curves for the Novosibirsk HPP and the equivalent TPP. It should be noted that when constructing the marginal cost curve for hydropower plants, restrictions on the throughput of the turbine and the power of the generator were taken into account.

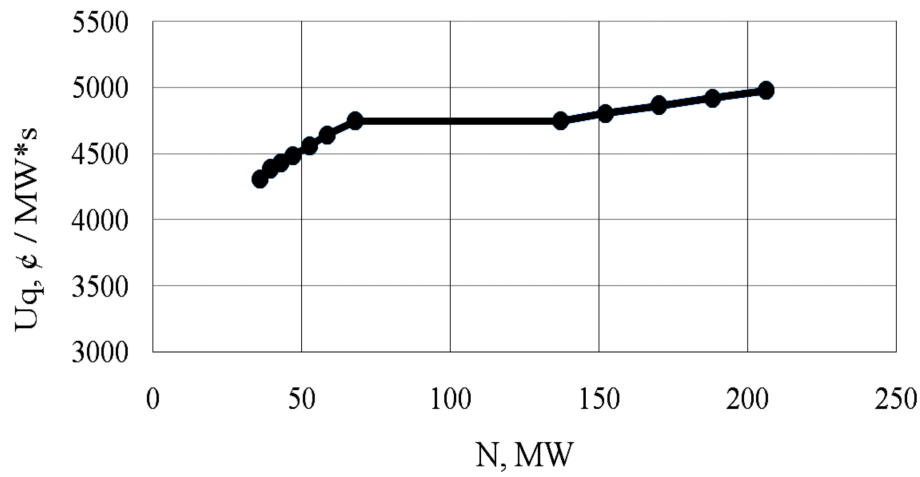

Figure 19. Marginal costs characteristic for the Novosibirsk HPP with its operation under the head of $H=17.5 \mathrm{~m}$.

Further, using expression (18), we find the optimal production volumes of the Novosibirsk HPP for each season of the year. The calculation results are summarized in Table 3.

Table 3. Optimization of the operating modes of the NHPP for each seasons of year.

\begin{tabular}{cccc}
\hline Season & HPP Parameters at $\boldsymbol{H = 1 4 . 0 5} \mathbf{~ m}$ & HPP Parameters at $\boldsymbol{H}=\mathbf{1 7 . 5} \mathbf{~ m}$ & HPP Parameters at $\boldsymbol{H}=\mathbf{1 7 . 9} \mathbf{~ m}$ \\
\hline Power, MW & 305 & 70 & 124 \\
Electric energy, MW.h & 219,600 & 50,400 & 89,280 \\
Sale price, $\not$ /MW.h & 4800 & 5048 & 4933 \\
Revenue, $\not$ & $3,162,240,000$ & $1,780,934,400$ & $880,896,000$ \\
\hline
\end{tabular}

Calculations showed that the cost of a hydro resource for the Novosibirsk HPP turned out to be comparable to the price of fuel at an equivalent Novosibirsk CHPP, which indicates the adequacy of the developed methodology.

Knowing the cost of a hydro resource and using the expression (an example is shown a graph of marginal costs for a head value $H=17.9 \mathrm{~m}$. (See Figures 18 and 19), we can build a marginal cost curve for the Novosibirsk hydropower plant

Further, using the criterion in the low-water season (see Figure 20), optimal operating modes of NHPP by seasons of the year are shown to maximize profits (Figure 1); we obtain the most favorable operating mode of the Novosibirsk HPP in Table 3. 


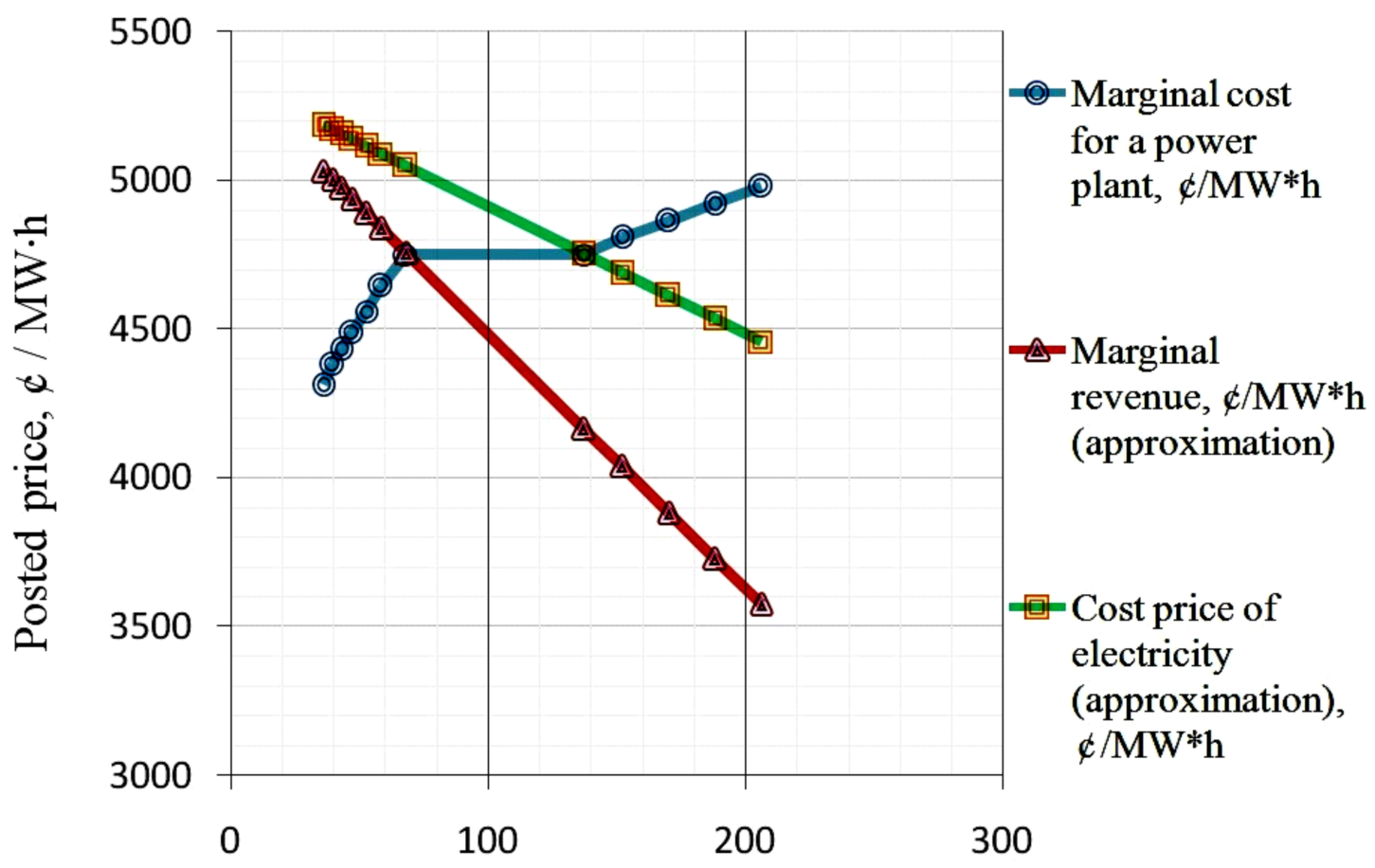

\section{$\mathrm{N}, \mathrm{MW}$}

Figure 20. Optimization of the operating modes of the NHPP for the low-water period $(H=17.5 \mathrm{~m})$.

In contrast to the methodology of indefinite Lagrange multipliers, the definition of the methodology allows you to determine the corresponding values on the differential characteristic for the HPP and the fuel consumption at the equivalent TPP for one iteration of the sequential construction of an indifference line based on the use of the theory of marginal utility, which is the effectiveness of the developed methodology for calculating the results of machine time for solution of the problem [52,53]. Moreover, it allows the obtainment of variability during the day without resorting to the use of complex algorithms.

Based on the results of validation with the technique of indefinite Lagrange multipliers, this technique showed a positive result and an increase in the share of HPPs in covering the power system capacity balance by $12 \%$, which will allow the region to implement an energy-saving policy in terms of a lower load of an equivalent TPP and improve the environmental situation in the region.

According to the method of indefinite Lagrange multipliers for the filling period, we obtain the following power distribution in the power system (Figure 21) [5].

It can be noted that the results of optimizing the operating modes of the Novosibirsk energy system, obtained by the new method, are within the range obtained by the method of indefinite Lagrange multipliers [51-53,58]. This proves the correctness of the developed algorithm and the adequacy of the results obtained.

At the same time an increase in the share of HPP generation in the daily energy balance of the EPS indicates the effectiveness of the application of the methodology from the standpoint of the environmental and economic criterion proposed by the authors.

For the algorithm proposed by the authors, the results are shown in Figure 22. 


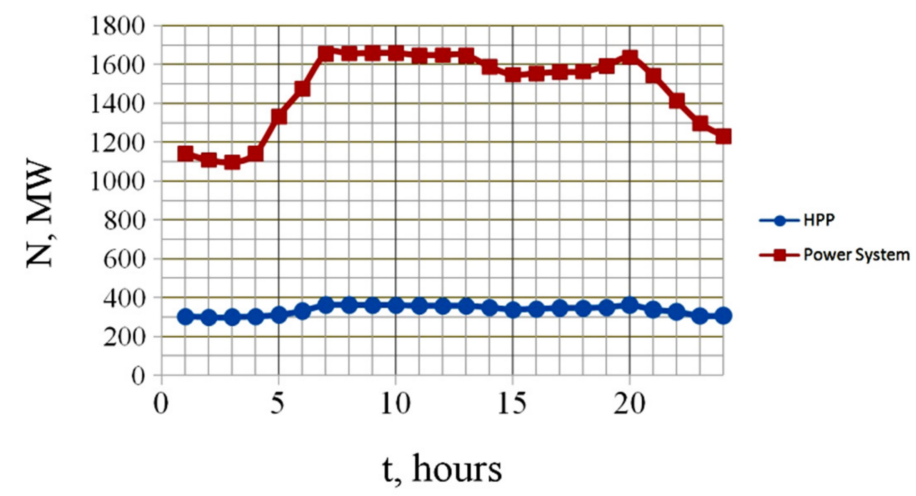

Figure 21. Load distribution in hydrothermal EPS by the Lagrangian method for the filling period.

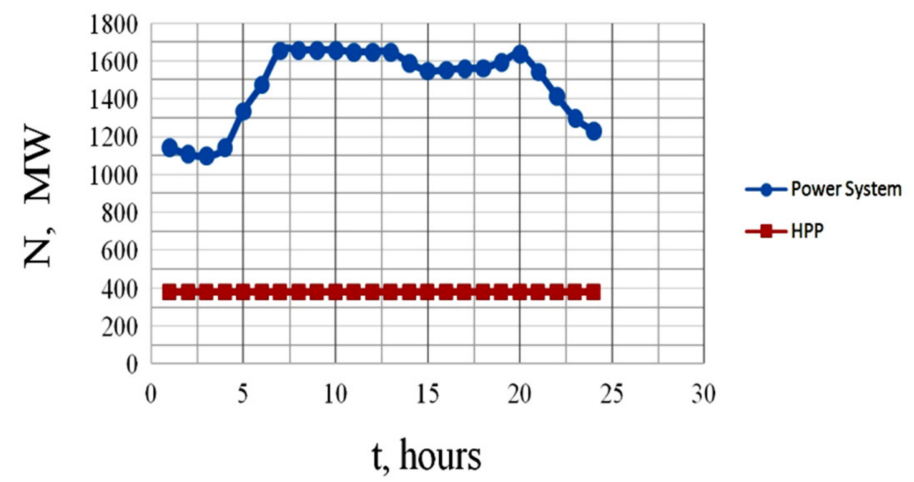

Figure 22. Power distribution in the hydropower system by the marginal utility method for the period of filling.

\section{Discussion}

Since the role of environmentally friendly technologies is increasing in modern circumstances, the topic of this work is as relevant as possible, since it involves solving the problems of investigating the models for optimal control of the hydro resource of the entire water-economic complex based on determining the cost of the hydro resource, taking into account the operational characteristics of the HPP. In turn, this will contribute to solving the problems of the energy saving of primary energy resources such as coal, gas, oil and fuel by displacing thermal power plants from hydropower plants as a more environmentally friendly source.

As the analysis of the conducted research shows, when using the developed methodology, the share of HPPs in the mixed energy system increases by $12 \%$, which improves the environmental performance of the region and the country as a whole.

At the same time, as shown in Table 2, based on the results of the author's technique, it is possible to solve the following problems: (1) to determine the optimal range of electricity generation at the station at a tariff that is added in the modern conditions of their operation; (2) to reasonably determine the value of the declared price for electricity on the basis of its optimal generation. This is shown in Figure 20, which shows a graphical display of the criterion of environmental and economic efficiency, which will make it possible to increase the competitiveness of HPPs at which, the cost of generating electricity is lower than at an equivalent TPP.

The relevance of these tasks especially increases with the transition to market liberalization, when, in order to maintain competitiveness, each station will strive not only to ensure reliable power supply for the consumer, with energy of a specified quality at any time, but also to achieve its commercial goals—-to maximize profits (see Table 3). 
Analysis of the mathematical model developed by the authors (expressions (10)-(18)) shows that according to the approach proposed by the authors, the number of steps of the problem being solved is significantly reduced, as is machine time to solve the problem when compared with the method of indefinite Lagrange multipliers using the coefficient $\lambda$ (one iteration versus five in the method of indefinite Lagrange multipliers).

Water resource price for NHPPs (see Table 2), which can be calculated using expression (16), is comparable to the cost of fuel at the TPP, which indicates the correctness of the calculations. An equation has also been derived to determine the cost of water for each participant of the water-economic complex (expression (22)), which will allow solving optimization problems for the entire water-economic complex of the country, thereby raising the technical and economic indicators of the entire country, as well as contributing to the solution of ecological and energy-saving tasks due to the complex nature of the criterion proposed by the authors (see Figure 1).

So the cost of water at the NHPP for the drawdown period is $0.211 \AA / \mathrm{m}^{3} / \mathrm{c}$. If we translate it into hours, we see that $0.211 \times 3600=759.6 \notin / \mathrm{m}^{3}$. This is of the same order as cost of 1 ton of brown coal, which is $690-980$ rubles per ton for a specific season of the year.

If we calculate the cost for Kuznetsk coal at the TPP, then we see that for the operating period at the NGES $-0.211 \times 3600=759.6 \not / \mathrm{m}^{3}$, which is half the cost of 1 ton of Kuznetsk coal, equal to $1600 \notin$ per ton. This indicates the adequacy of the approach proposed by the authors, since it will supplant the less environmentally friendly and economical TPP HPP.

Thus, the cost of a hydro resource will compensate for the damage caused to nature (areas of flooded lands, etc.) and provide a careful and ecological approach to solving many technological issues.

Moreover, there is no need to apply the efficiency factor of the use of energy resources $\lambda$ through the use of the theory of marginal utility, since the authors have developed a new rule for the transition from a relative increase in water consumption at hydropower plants to a relative increase in fuel consumption at thermal power plants, which lie on the same line of indifference. They also proposed to use their monetary equivalents (marginal costs) instead of physical quantities, which better reflect the technical and economic nature of the optimization process.

Moreover, it should be noted that the technique developed by the authors makes it possible to take into account the variability of the pressure and heads during the day, which the traditional technique of indefinite Lagrange multipliers does not allow. It allows taking into account the different value of $1 \mathrm{~m}^{3}$ of water during different time intervals of the entire optimization period [5].

At the same time, the solution of a number of resource-saving tasks will ensure a careful attitude to water resources, and hence a reduction in the harmful impact of humans on nature.

To find the volume of water that will be required to generate a guaranteed volume of production by the $i$-th industry, it is necessary to note the found value of $\mathrm{Ni}$ on the flow characteristic of the HPP, and then compare it with the value of water consumption $Q_{i}$ for each sector of the national economy. A hydro resource price for each branch is determined by expression (22).

\section{Conclusions}

According to the results of the research carried out, the following can be noted: a patent-oriented search for existing criteria for optimizing mixed energy systems was carried out and a criterion for calculating the price of water for WHC was created. The analysis of the traditional method of more optimal power distribution in a mixed power system was carried out using the method of indefinite Lagrange multipliers, and its shortcomings associated with the multiplicity of iterations and the duration of the process were identified. Separately, it is necessary to remark upon the condition $H=$ const, which takes place during the day as an assumption of this method. However, during the day, the pressure at a hydropower station is volatile. When defining the optimization conditions, as a rule, 
the change in pressure per day (with operational control) is not considered; a fundamentally new technique for the analysis and study of the modes of hydrothermal energy systems has been created; at the same time, the technological and economic features of electricity generation at HPPs are better taken into account due to the development of a new rule for the transition from relative increases in water consumption at HPP to fuel consumption at TPPs. There is also an improvement in the convergence of the process and a reduction in computing resources by reducing the volume of iterations performed (the solution is obtained in one action). Society develops a more careful attitude to the environment by increasing the share of HPPs in the energy balance of the regions and the country as a whole. All this is a consequence of the optimization carried out at the HPP and in the water-economic complex according to the method proposed by the authors using the theory of marginal utility. Thanks to this, it is possible to solve problems, improving the ecological situation in the country, as well as to implement energy saving policies. Thus, the share of Novosibirsk HPP in covering the energy balance of the region has grown by about $12 \%$, and the cost of a hydro resource at an HPP is comparable to the price of fuel at an equivalent TPP. The average price in the period of drawdown is $p_{\text {water }}($ drawdown $)=0.211 \mathrm{C} / / \mathrm{m}^{3} / \mathrm{s}$, the average price in the low-water period is $p_{\text {water (low-water) }}=0.1284 \mathrm{C} / / \mathrm{m}^{3} / \mathrm{s}$ and the average price in the natural afflux period is $p_{\text {water (natural afflux) }}=0.159 \mathrm{C} / / \mathrm{m}^{3} / \mathrm{s}$.

Thus, the mathematical model proposed by the authors is suitable for control and analysis of both modes of operation of mixed power systems based on the determination of the cost of the hydro resource, and the entire water-chemical complex as a whole.

\section{Patents}

As a result of the work, a patent was received: "Method of fuel costs separation at $\mathrm{CHP}^{\prime \prime}$.

Author Contributions: Conceptualization, Y.S. and T.M.; methodology, Y.S., T.M., A.G. and M.S.; software, T.M.; validation, Y.S.; formal analysis, Y.S., T.M. and S.M.; investigation, Y.S., T.M. and N.Z.; resources, Y.S. and T.M.; data curation, Y.S.; writing-original draft preparation, Y.S., T.M. and O.A.; writing-review and editing, Y.S., T.M. and S.M.; visualization, S.M., X.C., A.G. and M.S.; supervision, Y.S., T.M., A.G. and M.S.; project administration, Y.S., T.M., A.G. and M.S.; funding acquisition, A.G. and X.C. All authors have read and agreed to the published version of the manuscript.

Funding: This work was supported in part by the International Cooperation Project of National Natural Science Foundation of China under Grant 41761144079, in part by the Strategic Priority Research Program of the Chinese Academy of Sciences, Pan-Third Pole Environment Study for a Green Silk Road under Grant XDA20060303, in part by the K. C. Wong Education Foundation under Grant GJTD-2020-14, in part by the Research Fund for International Scientists of National Natural Science Foundation of China under Grant 42150410393, in part by the CAS PIFI Fellowship under Grant 2021PC0002, in part by the Xinjiang Tianchi Hundred Talents Program under Grant Y848041, in part by the CAS Interdisciplinary Innovation Team under Grant JCTD-2019-20, in part by the project of the Research Center of Ecology and Environment in Central Asia under Grant Y934031, and in part by the Regional Collaborative Innovation Project of Xinjiang Uygur Autonomous Regions under Grant 2020E01010.

Informed Consent Statement: Informed consent was obtained from all subjects involved in the study.

Data Availability Statement: https: / www.rushydro.ru (accessed on 1 February 2022).

Conflicts of Interest: The authors declare no conflict of interest. 


\section{Abbreviations}

Abbreviation
HPP
WEC
TPP
UPS
WUS
EPS
CHHP
DC
FOREM
JSC-energo
JSC-power plants
TSO grid services
DSO grid services
MR
MC
DM
WUC
H
WMC
NHPP
WECAL

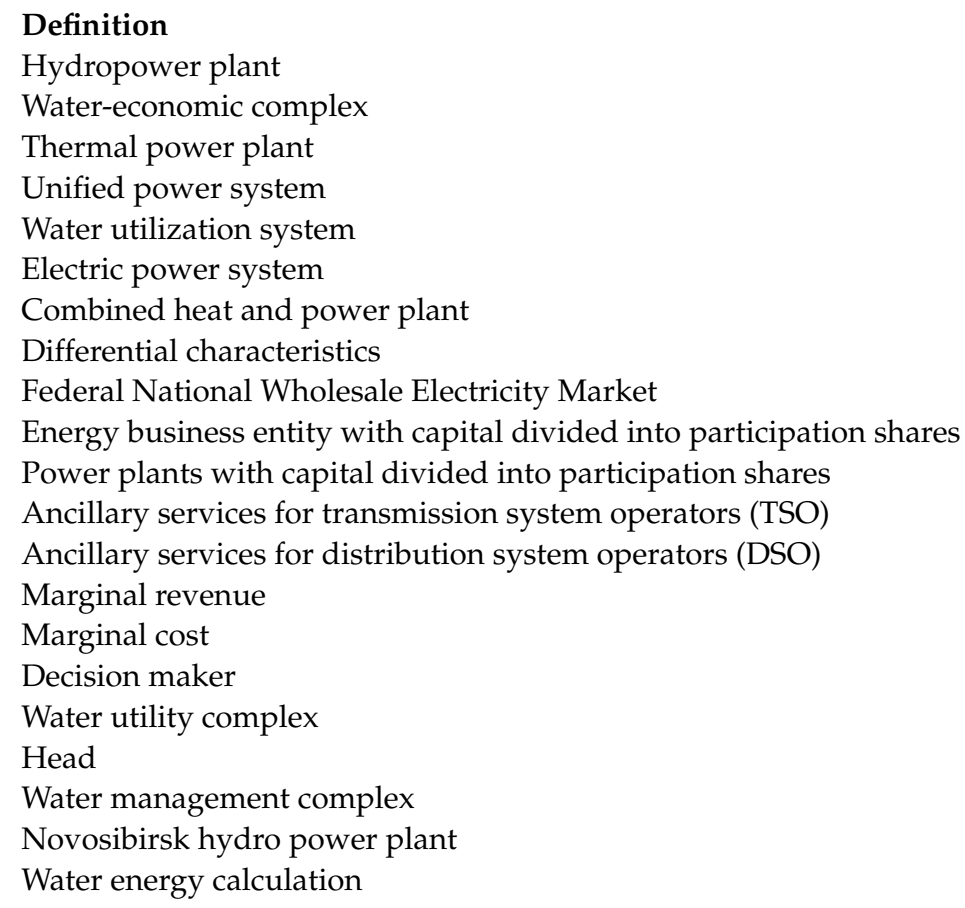

\section{References}

1. Government of the Russian Federation. Energy Strategy for the Development of the Russian Federation for the Period up to 2035; No. 1523-r; Government of the Russian Federation: Moscow, Russia, 2020.

2. McConnell, C.R.; Bru, S.L. Economics: Principles, Problems and Politics; Infra-M: Moscow, Russia, $1997 ;$ Volume 2.

3. Galperin, V.M. The Theory of Consumer Behavior and Demand; Economic School Publishing House: Saint Petersburg, Russia, 1993; 380p.

4. Galperin, V.M.; Ignatyev, S.M.; Morgunov, V.I. Microeconomics; Economic School: Saint Petersburg, Russia, $1997 ;$ Volume 1.

5. Filippova, T.A.; Misrikhanov, M.S.; Sidorkin, Y.M.; Rusina, A.G. Hydropower; Textbook; Novosibirsk State Technical University (NSTU): Novosibirsk, Russia, 2011; 640p.

6. Sekretarev, Y.A.; Sultonov, S.M. Optimal Management of HPP Regimes in Electric Power Systems; Monograph; Tajik Technical University Named after Academic M.S. Osimi (TTU): Dushanbe, Tajikistan, 2020; 144p.

7. Mitrofanov, S.V.; Sekretarev, Y.A.; Sultonov, S.M. Implementation of the method of Lagrange for optimal modes of energy system of Tajikistan. Appl. Mech. Mater. 2015, 698, 726-731.

8. Štefan, Ž.; Brezovec, M.; Munđar, D. A decision support system for hydro power plants in markets for energy and ancillary services. In Proceedings of the 8th International Conference on the European Energy Market (EEM), Zagreb, Croatia, 25-27 May 2011; pp. 442-447. [CrossRef]

9. Sovban, E.A.; Filippova, T.A.; Panteleev, V.I.; Trufakin, S.S. The Features of mathematical optimization models of modes hydropower stations. In Proceedings of the XIV International Scientific-Technical Conference on Actual Problems of Electronics Instrument Engineering (APEIE), Novosibirsk, Russia, 2-6 October 2018; pp. 428-432. [CrossRef]

10. Kolesnikov, A.A.; Kikin, P.M.; Panidi, E.A.; Rusina, A.G. Using systems of parallel and distributed data processing to build hydrological models based on remote sensing data. In Proceedings of the 24 ISPRS Congress-Electronic Imaging Today, Foreseeing Tomorrow, Nice, France, 5-9 July 2021; Volume 43, pp. 111-116. [CrossRef]

11. Catalao, J.P.S.; Pousinho, H.M.I.; Mendes, V.M.F. Hydro energy systems management in Portugal: Profit based evaluation of a mixed-integer nonlinear approach. Energy 2011, 36, 500-507. [CrossRef]

12. Osorio, G.J.; Matias, J.C.O.; Catalao, J.P.S. A review of short-term hydro scheduling tools. In Proceedings of the 48th International Universities Power Engineering Conference (UPEC), Dublin, Ireland, 2-5 September 2013. [CrossRef]

13. Finardi, E.C.; da Silva, E.L. Solving the hydro unit commitment problem via dual decomposition and sequential quadratic programming. IEEE Trans. Power Syst. 2006, 21, 835-844. [CrossRef]

14. Ferrero, R.; Rivera, J.; Shahidehpour, S. A Dynamic Programming Two-Stage Algorithm for Long-term Hydrothermal Scheduling of Multireservoir System II. IEEE Trans. Power Syst. 1998, 13, 1534-1540. [CrossRef]

15. Mitrofanov, S.V.; Khalyasmaa, A.I.; Eroshenko, S.A.; Rusina, A.G.; Arestova, A.Y.; Sidorova, A.V. Development of a simulation model of HPPs chain operation. In Proceedings of the 3rd International Conference on Renewable Energy and Environment Engineering (REEE 2020), Lisbon, Portugal, 16-18 August 2020; Volume 191. [CrossRef] 
16. Mitrofanov, S.V.; Khalyasmaa, A.I.; Eroshenko, S.A.; Arestova, A.Y.; Rusina, A.G.; Kolesnikov, A. Integrating GIS technologies in hydro power plant cascade simulation model. In Proceedings of the 3rd International Conference on Renewable Energy and Environment Engineering (REEE 2020), Lisbon, Portugal, 16-18 August 2020; Volume 191. [CrossRef]

17. Baležentis, T.; Štreimikienè, D. Sustainability in the Electricity Sector through Advanced Technologies: Energy Mix Transition and Smart Grid Technology in China. Energies 2019, 12, 1142. [CrossRef]

18. Kumar, J.; Khalil, I.U.; Haq, A.U.; Perwaiz, A.; Mehmood, K. Solver-Based Mixed Integer Linear Programming (MILP) Based Novel Approach for Hydroelectric Power Generation Optimization. IEEE Access 2020, 8, 174880-174892. [CrossRef]

19. Jiang, Z.; Ji, C.; Qin, H.; Feng, Z. Multi-stage progressive optimality algorithm and its application in energy storage operation chart optimization of cascade reservoirs. Energy 2018, 148, 309-323. [CrossRef]

20. Liao, X.; Zhou, J.; Ouyang, S.; Zhang, R.; Zhang, Y. Multi-objective artificial bee colony algorithm for long-term scheduling of hydropower system: A case study of china. Water Util. J. 2014, 7, 13-23.

21. Sharma, R.N.; Narottam, C.; Veena, S.; Deepika, Y. Decision support system for operation, scheduling and optimization of hydro power plant in Jammu and Kashmir region. Renew. Sustain. Energy Rev. 2015, 43, 1099-1113. [CrossRef]

22. Fallahia, A.; Ebrahimib, R.; Ghaderic, S.F. Measuring efficiency and productivity change in power electric generation management companies by using data envelopment analysis: A case study. Energy 2011, 36, 6398-6405. [CrossRef]

23. Zenga, Z.; Nasric, E.; Chinib, A.; Riesb, R.; Xu, J. A multiple objective decision making model for energy generation portfolio under fuzzy uncertainty: Case study of large scale investor-owned utilities in Florida. Renew. Energy 2015, 75, 224-242. [CrossRef]

24. Oak Ridge National Laboratory (ORNL). Hydropower Baseline Cost Modeling; Oak Ridge National Laboratory (ORNL): Oak Ridge, TN, USA, 2015. Available online: https://info.ornl.gov/sites/publications/files/Pub53978.pdf (accessed on 1 February 2022).

25. Çelikdemir, S.; Yıldırım, B.; Özdemir, M.T. Cost analysis of mini hydro power plant using bacterial swarm optimization. Int. J. Energy Smart Grid 2017, 2, 64-81. [CrossRef]

26. Ghaderi, S.F.; Azadeh, A.; Nokhandan, B.P.; Fathi, E. Behavioral simulation and optimization of generation companies in electricity markets by Fuzzy cognitive map. Expert Syst. Appl. 2012, 39, 4635-4646. [CrossRef]

27. Rusina, A.G.; Filippova, T.A.; Savban, E.A.; Khujasaidov, J.K. Basics of technique evaluation the use of hydroelectric resources in their work in eps. J. Sib. Fed. Univ. Eng. Technol. 2017, 10, 426-434. [CrossRef]

28. Zorkaltsev, V.I.; Khamisov, O.V. Equilibrium Models in Economics and Power Industry; Nauka: Novosibirsk, Russia, 2006; 221p.

29. Mahnitko, A.; Gerhards, J.; Lomane, T.; Varfolomejeva, R.; Oboskalov, V. A model for maximizing the profit of a HPP cascade considering hydraulic link via reservoirs. In Proceedings of the IEEE 16th International Conference on Environment and Electrical Engineering (EEEIC), Florence, Italy, 7-10 June 2016; pp. 1-5.

30. Rodriguesm, R.N.; Finardi, E.C.; da Suva, E.L. Optimal dispatch of hydro generation plants via augmented Lagrangian. In Proceedings of the IEEE Power Engineering Society General Meeting, San Francisco, CA, USA, 12-16 June2005; Volume 3, pp. 2732-2737. [CrossRef]

31. Conejo, A.J.; Redondo, N.J. Short-term hydro-thermal coordination by relaxation Lagrangian: Solution of the dual problem. IEEE Trans. Power Syst. 1999, 14, 89-95.

32. Guan, X.; Luh, P.B.; Zhang, L. Nonlinear approximation method in Lagrangian relaxation-based algorithms for hydrothermal scheduling. IEEE Trans. Power Syst. 1995, 10, 772-778. [CrossRef]

33. Zhai, Q.; Guan, X.; Cui, J. Unit commitment with identical units: Successive subproblem solving method based on Lagrangian relaxation. IEEE Trans. Power Syst. 2002, 17, 1250-1257. [CrossRef]

34. Government of the Russia. Development of Land Reclamation of Agricultural Lands in Russia for 2012-2020; Government of the Russia: Moscow, Russia, 2012.

35. Government of the Russia. Development of Land Reclamation of Agricultural Lands in Russia for 2014-2020; Government of the Russia: Moscow, Russia, 2013

36. Sovban, E.A.; Rusina, A.G. Development of management method for the power electricity mode of the electric power system of Siberia with the significant share of hydro power stations. In Electric Power Industry through the Eyes of Young People; Ministry of Energy of the Russia: Moscow, Russia, 2018; pp. 186-189.

37. Yuan, W.; Wang, J.; Qiu, F.; Chen, C.; Kang, C.; Zeng, B. Robust optimization-based resilient distribution network planning against natural disasters. IEEE Trans. Smart Grid 2016, 7, 2817-2826. [CrossRef]

38. Aravena, I.; Rajan, D.; Patsakis, G.; Oren Rios, J. A Scalable Mixed-Integer Decomposition Approach for Optimal Power System Restoration. IEEE Trans. Power Syst. 2019, unpublished. Available online: http:/ / www.optimization-online.org/DB_HTML/2019 /02/7062.html (accessed on 1 February 2022).

39. Garifi, K.; Johnson, E.S.; Arguello, B.; Pierre, B.J. Transmission Grid Resiliency Investment Optimization Model with SOCP Recovery Planning. IEEE Trans. Power Syst. 2022, 37, 26-37. [CrossRef]

40. Skvortsova, O.; Dashkina, A.; Petrovskaia, E.; Terleev, V.; Nikonorov, A.; Badenko, V.; Volkova, Y.; Pavlov, S. The classification of accidental situations scenarios on hydropower plants. MATEC Web Conf. 2016, 53, 01014. [CrossRef]

41. Török, G.; Csík, M.; Pintér, A.; Surján, A. Effects of different deuterium concentrations of the media on the bacterial growth and mutagenesis. Egészségtudomány 2000, 44, 331-338. (In Hungarian)

42. Wang, Q.; Wei, W.; Gong, Y.; Yu, Q.; Li, Q.; Sun, J.; Yuan, Z. Technologies for reducing sludge production in wastewater treatment plants: State of the art. Sci. Total Environ. 2017, 587-588, 510-521. [CrossRef] 
43. Collivignarelli, M.C.; Abbà, A.; Miino, M.C.; Torretta, V. What Advanced Treatments Can Be Used to Minimize the Production of Sewage Sludge in WWTPs? Appl. Sci. 2019, 9, 2650. [CrossRef]

44. Li, F.-F.; Qiu, J. Multi-Objective Reservoir Optimization Balancing Energy Generation and Firm Power. Energies 2015, 8 , 6962-6976. [CrossRef]

45. Ivanova, E.V. Analysis of the efficiency of using solar power plants and wind turbines to provide electricity for the economic needs of NGES. In Science, Technologies, Innovations; Part 4; Ivanova, E.V., Zubova, N.V., Eds.; Novosibirsk State Technical University (NSTU): Novosibirsk, Russia, 2019; pp. 35-38.

46. Zhang, Z.; Wang, Z.; Chen, Z.; Wang, G.; Shen, N.; Guo, C. Study on Grid-Connected Strategy of Distribution Network with High Hydropower Penetration Rate in Isolated Operation. Processes 2019, 7, 328. [CrossRef]

47. Sysoev, A.A.; Lazareva, N.V.; Proskurina, A.A. Modeling complex hydropower systems for research and training. In Proceedings of the International Conference on Industrial Engineering, Applications and Manufacturing (ICIEAM), Sochi, Russia, 17-21 May 2021; pp. 152-157. [CrossRef]

48. Panteleev, V.I.; Trufakin, S.S.; Pilyugin, G.A. Stochastic optimization of modes of hydroelectric power plants. In Proceedings of the International Conference on Industrial Engineering, Applications and Manufacturing (ICIEAM), Sochi, Russia, 25-29 March 2019; pp. 1-5. [CrossRef]

49. Kelman, M.R.; Pereira, M.; Campodónico, N. Long-term hydro scheduling based on stochastic models. In Proceedings of the International Conference on Electrical Power Systems Operation and Management (EPSOM), Zurich, Switzerland, 23-25 September 1998; Volume 98, pp. 23-25.

50. Li, C.-A.; Svoboda, A.J.; Tseng, C.-L.; Johnson, R.B.; Hsu, E. Hydro unit commitment in hydro-thermal optimization. IEEE Trans. Power Syst. 1997, 12, 764-769. [CrossRef]

51. Myateg, T.V.; Sekretarev, Y.A. Determination of the price for a hydro resource with consideration of operating conditions of hydropower plants using complex criteria of profit maximization. Int. J. Electr. Comput. Eng. 2021, 11, $2733-2742$.

52. Sekretarev, Y.A.; Myatezh, T.V.; Gorshin, A.V. Justification of the water price at hydropower plants based on its operational features according to the maximization profit criteria. In Proceedings of the International Multi-Conference on Industrial Engineering and Modern Technologies (FarEastCon), Vladivostok, Russia, 6-9 October 2020; Institute of Electrical and Electronics Engineers (IEEE): Piscataway, NJ, USA, 2020. [CrossRef]

53. Sekretarev, Y.A.; Myatezh, T.V.; Gorshin, A.V. Optimization of operating modes of hydropower plants with determination of the price for a hydro resource using complex criteria of ecological and economic efficiency. IOP Conf. Ser. Mater. Sci. Eng. 2021, 1089, 012038. [CrossRef]

54. Moshkin, B.N.; Myatezh, T.V.; Sekretarev, Y.A.; Averbukh, M.A. Mathematical model of managing of the generating company on the criterion of the profit maximization. IOP Conf. Ser. Mater. Sci. Eng. 2019, 552, 012016. [CrossRef]

55. Sekretarev, Y.A.; Chekalina, T.V.; Malosemov, B.V. Administration functioning power generation companies by criterion of maximization profit. In Proceedings of the 6th International Forum on Strategic Technology (IFOST-2011), Harbin University of Science and Technology, Harbin, China, 22-24 August 2011; Volume 1, pp. 491-494.

56. Sekretarev, Y.A.; Chekalina, T.V.; Moshkin, B.N. Administration functioning power generation companies based on thermal electrical power station on maximization profit criterion. Proc. High. Educ. Inst. Electromech. 2016, 4, 82-88. [CrossRef]

57. Zhao, T.; Zhao, J.; Liu, P.; Lei, X. Evaluating the marginal utility principle for long-term hydropower scheduling. Energy Convers. Manag. 2015, 106, 213-223. [CrossRef]

58. Secretarev, Y.A.; Myateg, T.V.; Baldakova, T.E. Model of Optimal Load Control for Electric Power Stations in a Hydrothermal Power System on the Basis of Maximization Profit Criteria. In Proceedings of the Ural-Siberian Smart Energy Conference (USSEC), Novosibirsk, Russia, 13-15 November 2021. [CrossRef] 